\title{
Benchmarking analogue models of brittle thrust wedges
}

\author{
Schreurs Guido ${ }^{1,{ }^{*}}$, Buiter Susanne J. H. ${ }^{2,3}$, Boutelier Jennifer ${ }^{4}$, Burberry Caroline ${ }^{5,24}$, \\ Callot Jean-Paul ${ }^{6,25}$, Cavozzi Cristian ${ }^{7}$, Cerca Mariano ${ }^{8}$, Chen Jian-Hong ${ }^{9}$, Cristallini Ernesto ${ }^{10}$, \\ Cruden Alexander R. ${ }^{11,26}$, Cruz Leonardo ${ }^{12}$, Daniel Jean-Marc ${ }^{6,32}$, Da Poian Gabriela ${ }^{10,27}$, \\ Garcia Victor H. ${ }^{10,27}$, Gomes Caroline J. S. ${ }^{13}$, Grall Celine ${ }^{6,28}$, Guillot Yannick ${ }^{14}$, Guzman Cecilia ${ }^{10}$, \\ Hidayah Triyani Nur ${ }^{15}$, Hilley George ${ }^{16}$, Klinkmuller Matthias ${ }^{1}$, Koyi Hemin A. ' ${ }^{5}$, Lu Chia-Yu ${ }^{17}$, \\ Maillot Bertrand ${ }^{18}$, Meriaux Catherine ${ }^{29}$, Nilfouroushan Faramarz ${ }^{30}$, Pan Chang-Chih ${ }^{9}$, Pillot Daniel ${ }^{6}$, \\ Portillo Rodrigo ', Rosenau Matthias ${ }^{20}$, Schellart Wouter P. ${ }^{19}$, Schlische Roy W. ${ }^{15}$, Take Andy ${ }^{21}$ ', \\ Vendeville Bruno ${ }^{22}$, Vergnaud Marine ${ }^{6}$, Vettori Matteo ${ }^{7,31}$, Wang Shih-Hsien ${ }^{9}$, Withjack Martha O. ' ${ }^{15}$, \\ Yagupsky Daniel ${ }^{10}$, Yamada Yasuhiro ${ }^{23}$
}

${ }^{1}$ Univ Bern, Inst Geol Sci, Baltzerstr 1 \& 3, CH-3012 Bern, Switzerland.

${ }^{2}$ Geol Survey Norway, Geodynam Team, N-7491 Trondheim, Norway.

3 Univ Oslo, Ctr Earth Evolut \& Dynam, POB 1048, N-0316 Oslo, Norway.

${ }^{4}$ Univ Toronto, Dept Geol, 22 Russell St, Toronto, ON M5S 3B1, Canada.

${ }^{5}$ Uppsala Univ, Dept Earth Sci, Hans Ramberg Tecton Lab, S-75326 Uppsala, Sweden.

${ }^{6}$ IFP Energies Nouvelles, 1 \& 4 Ave Bois Preau, F-92500 Rueil Malmaison, France.

${ }^{7}$ Univ Parma, Dept Phys \& Earth Sci Macedonio Melloni, NEXT Nat \& Expt Tecton Res Grp, Via G Usberti 157-A, I-43100 Parma, Italy.

${ }^{8}$ Univ Nacl Autonoma Mexico, Ctr Geociencias, Blvd Juriquilla 3001, Juriquilla 76230, Queretaro, Mexico.

${ }_{9}^{9}$ Natl Taiwan Univ, Dept Geosci, 1 Roosevelt Rd Sect 4, Taipei 106, Taiwan.

${ }^{10}$ Univ Buenos Aires, Dept Ciencias Geol, Pabellon 2, Ciudad Univ,C1428EHA, Buenos Aires, DF,

Argentina.

${ }^{11}$ Univ Toronto, Dept Geol, 22 Russell St, Toronto, ON M5S 3B1, Canada.

12 Stanford Univ, Dept Geol \& Environm Sci, Braun Hall 215, Stanford, CA 94305 USA.

${ }_{13}^{13}$ Univ Fed Ouro Preto, Dept Geol, Morro Cruzeiro S-N 35, BR-400000 Ouro Preto, MG, Brazil.

${ }_{15}^{14}$ Univ Lille Nord France, Lab Geosyst, FRE CNRS 3298, F-59655 Villeneuve Dascq, France.

${ }^{15}$ Rutgers State Univ, Dept Earth \& Planetary Sci, 610 Taylor Rd, Piscataway, NJ 08854 USA.

${ }^{16}$ Stanford Univ, Dept Geol \& Environm Sci, Braun Hall 233, Stanford, CA 94305 USA.

${ }_{17}^{17}$ Natl Taiwan Univ, Dept Geosci, 1 Roosevelt Rd, Taipei 106, Taiwan.

${ }^{18}$ Univ Cergy Pontoise, Lab Geosci \& Environm Cergy, 5 Mail Gay Lussac, F-95031 Neuville Sur Oise, Cergy Pontoise, France.

${ }^{19}$ Monash Univ, Sch Earth Atmosphere \& Environm, Melbourne, Vic 3800, Australia.

${ }^{20}$ Helmholtz Ctr Potsdam, GFZ German Res Ctr Geosci, D-14473 Potsdam, Germany.

${ }^{21}$ Queens Univ, Dept Civil Engn, Kingston, ON K7L 3N6, Canada.

22 Univ Lille, UMR 8187, LOG, F-59000 Lille, France.

${ }^{23}$ Kyoto Univ, Dept Civil \& Earth Resources Engn, Kyoto 6158540, Japan.

${ }^{24}$ Univ Nebraska Lincoln, Dept Earth \& Atmospher Sci, 214 Bessey Hall,POB 880340, Lincoln, NE 68588 USA.

${ }^{25}$ Univ Pau \& Pays Adour, Lab Fluides Complexes \& Leurs Reservoirs, UMR5150, BP 1155, F-64012

Pau, France.

${ }^{26}$ Monash Univ, Sch Earth Atmosphere \& Environm, Melbourne, Vic 3800, Australia.

${ }^{27}$ Univ Nacl Rio Negro, Inst Invest Paleobiol \& Geol, Isidro Lobo 516, RA-8332 Gen Roca, Rio Negro, Argentina. 
${ }^{28}$ Columbia Univ, Marine Geol \& Geophys, Lamont Doherty Earth Observ, Palisades, NY 10964 USA.

${ }^{29}$ Univ Lisbon, Dept Engn Geog Geofis \& Energia, P-1749016 Lisbon, Portugal.

${ }^{30}$ Univ Gavle, Dept Ind Dev IT \& Land Management, Gavle, Sweden.

${ }^{31}$ E FEM Srl, CAE Struct Anal \& Composite Design, CTO Area, Parma, Italy.

32 IFREMER, Dept Phys Resources \& Deep Sea Ecosyst PDG REM, Ctr Bretagne, ZI Pointe Diable, CS 10070, F-29280 Plouzane, France.

*Corresponding author : Guido Schreurs, email address : schreurs@geo.unibe.ch

\begin{abstract}
:
We performed a quantitative comparison of brittle thrust wedge experiments to evaluate the variability among analogue models and to appraise the reproducibility and limits of model interpretation. Fifteen analogue modeling laboratories participated in this benchmark initiative. Each laboratory received a shipment of the same type of quartz and corundum sand and all laboratories adhered to a stringent model building protocol and used the same type of foil to cover base and sidewalls of the sandbox. Sieve structure, sifting height, filling rate, and details on off-scraping of excess sand followed prescribed procedures.
\end{abstract}

Our analogue benchmark shows that even for simple plane-strain experiments with prescribed stringent model construction techniques, quantitative model results show variability, most notably for surface slope, thrust spacing and number of forward and backthrusts. One of the sources of the variability in model results is related to slight variations in how sand is deposited in the sandbox. Small changes in sifting height, sifting rate, and scraping will result in slightly heterogeneous material bulk densities, which will affect the mechanical properties of the sand, and will result in lateral and vertical differences in peak and boundary friction angles, as well as cohesion values once the model is constructed. Initial variations in basal friction are inferred to play the most important role in causing model variability.

Our comparison shows that the human factor plays a decisive role, and even when one modeler repeats the same experiment, quantitative model results still show variability. Our observations highlight the limits of up-scaling quantitative analogue model results to nature or for making comparisons with numerical models. The frictional behavior of sand is highly sensitive to small variations in material state or experimental set-up, and hence, it will remain difficult to scale quantitative results such as number of thrusts, thrust spacing, and pop-up width from model to nature.

\title{
Highlights
}

- A quantitative comparison of thrust wedge models from 15 analogue modeling laboratories is presented. Analogue models show variability, most notably for surface slope, thrust spacing and number of forward and backthrusts. Model variability is most likely controlled by initial variations in basal friction. Our comparison highlight the limits of up-scaling quantitative analogue model results to nature.

Keywords : Thrust wedges, Brittle wedges, Shear zones, Analogue modeling, Benchmarking, Critical taper, Sand, Friction, Cohesion 
242 Scaled analogue experiments have a long history of modeling geological processes. Analogue 243 models built of materials such as sand, silicone or clay have helped geoscientists to gain 244 insights into the kinematic and dynamic evolution of a wide variety of geological structures. 245 However, as for all models, their results reflect the initial boundary conditions, the choice of 246 materials, the modeling apparatus and the technique of building the model. Unfortunately, 247 many publications on analogue modeling do not adequately record experimental details and 248 material properties, making a detailed comparison of model results among different 249 laboratories simulating similar geological processes difficult. Additionally, experiments are 250 rarely re-run to test the reproducibility and to determine the intrinsic variability of model 251 results.

Schreurs et al. (2006) were the first to report a direct comparison of scaled analogue experiments to test the reproducibility of model results amongst ten analogue modeling laboratories. One of the two experimental set-ups chosen in their comparison was a brittle thrust wedge experiment (Fig. 1). The experimental set-up, the model-building technique, and the material covering walls and base were all prescribed. However, each laboratory used its own granular material to simulate brittle deformation. Consequently, in the comparison of

The qualitative evolution of all models was broadly similar (Fig. 2) with the development of a 263 thrust wedge characterized by in-sequence forward thrusting and by minor back thrusting.

264 However, significant quantitative variations existed between models in parameters such as the spacing between thrusts, their dip angles, number of forward and back thrusts and surface 266 slopes. 
INSERT Fig. 1. Experimental set-up used in model comparison experiments by Schreurs et al., (2006). Model consists of a $3.5 \mathrm{~cm}$-thick sand layer with an embedded microbeads layer and an overlying sand wedge with a surface slope of $10^{\circ}$ adjacent to the mobile wall. All walls are covered by Alkor foil. Figure reproduced from Schreurs et al. (2006) with permission from the Geological Society of London.

INSERT Fig. 2. Model comparison showing crosssections through thrust wedge after 2, 6 and $14 \mathrm{~cm}$ of shortening. The experimental set-up is shown in Fig. 1. The sections of Bern and IFP Rueil Malmaison are X-ray computer tomography (XRCT) images through the center of the model, whereas the remaining sections are sidewall observations. Microbeads layer indicated by " $m$ ". Figure modified after and reproduced from Schreurs et al. (2006) with permission from the Geological Society of London.

In the analogue modeling comparison by Schreurs et al. (2006), each laboratory used its own granular material and differences existed in terms of material properties such as grain size, grain shape and grain size distribution. Hence, we suspect that the resulting inherent variations in material properties between the different labs may have been responsible for differences in the evolution of the experimental models. Lohrmann et al. (2003), for example, determined that the kinematics of thrust wedges is largely a function of their material properties. Differences in the observation techniques used to monitor the evolution of structures also contributed to model variability. Some research groups observed structures through transparent sidewalls, where sidewall friction is highest, whereas other labs used Xray $\mathrm{CT}$ (XRCT) techniques to observe model evolution at the center of the model, where the effects of sidewall frictional stresses are less.

The outcome of the analogue comparison study by Schreurs et al. (2006) motivated us to propose new comparison experiments, with the aim to better understand the variability between models by discriminating extrinsic versus intrinsic variability. The main differences with the previous analogue model comparison are that in the present study we not only prescribe stringent model-building techniques, but all participating laboratories use exactly

298 the same type of analogue materials for their experiments. By harmonizing boundary conditions and material properties we isolate intrinsic variability related to sources such as inherent randomness or other less obvious conditioning parameters (e.g., air humidity). 
experiments are thrust wedge experiments that have frequently been performed in the analog modeling community. We choose three different experiments, referred to as experiment 1,2 and 3, respectively. In each of these experiments deformation is imposed by displacement of one mobile, vertical wall. For practical reasons the maximum shortening is limited to $10 \mathrm{~cm}$. This allowed sand box dimensions to be smaller than for larger amounts of shortening, and thereby allowed more labs to participate. Fifteen analogue modeling laboratories joined in this comparison conducting the experiments in their local laboratory environment. In order to isolate the personal impact on experiments, two researchers ran models using the experimental apparatus from the laboratory in Bern. These models are referred to as "Bern" and “GFZ@Bern”, respectively.

In a companion paper, Buiter et al. (2016) present the results of a comparison of up to 11 numerical codes, simulating the same experimental set-ups, with the numerical material properties following the analogue material properties as closely as possible. Major sources of variability here are differences in the implementation of boundary conditions and subtle differences between numerical solvers.

\section{Modeling approach}

\subsection{Material properties}

Each laboratory received a shipment of the quartz and corundum sand that is routinely used at the analogue modeling laboratory of the Institute of Geological Sciences at the University of Bern. Laboratories were asked to store the sands in a dry place for at least one month before conducting experiments and to record room temperature and humidity during experimental runs.

\subsubsection{Physical characteristics}

The physical characteristics of the sands are summarized in Figure 3. The quartz sand is a natural Triassic sand from a quarry at Schnaittenbach (Germany), whereas the corundum sand is derived from bauxite. The quartz sand has a fairly homogeneous grain size distribution with $90 \%$ of the grains falling within the $125-175 \mu \mathrm{m}$ fraction. The brown corundum sand has a 
more heterogeneous grain size distribution with $70 \%$ of the grains falling between 88 and 125 $\mu \mathrm{m}$. Bulk density depends both on the material and on the physical handling technique, i.e. whether material is sieved or poured. As shown previously by Krantz (1991), Schellart (2000), Lohrmann et al. (2003), Panien et al. (2006), Gomes (2013) and Maillot (2013) the bulk density of sieved granular materials is higher than the bulk density of poured granular materials. In our experiments, the sands are sieved from a height of $20 \mathrm{~cm}$ using prescribed sieve (Appendix A-1) and sieving rates. The bulk densities of quartz and corundum sand sieved from $20 \mathrm{~cm}$ height are $1.6 \mathrm{~g} / \mathrm{cm}^{3}$ and $1.9 \mathrm{~g} / \mathrm{cm}^{3}$, respectively.

INSERT Fig. 3. Physical characteristics of the quartz and corundum sand used in the experiments (modified after Panien et al., 2006). Upper and lowermost images are photographs and SEM images, respectively. Width of each SEM image is $1740 \mu \mathrm{m}$.

\subsubsection{Friction angles and cohesion}

The mechanical properties of the sands have been determined with a ring-shear tester, model RST-01.pc (Schulze, 2008), at the GFZ in Potsdam. The sands were stored for one month prior to testing to adapt to the air-conditioned environment. Sand storage and ring-shear testing occurred at temperatures of $23 \pm 1^{\circ} \mathrm{C}$ and atmospheric humidity of $45 \pm 5 \%$. The ring-shear tester allows the determination of the internal and boundary friction angles of granular materials at low normal stresses similar to those observed in analog model experiments $(<20 \mathrm{kPa})$. The ring-shear tester consists of an annular shear cell holding the tested material, a normal loaded shear lid placed onto the cell, and tie rods measuring the shear stress. Using a ring-shear tester, Lohrmann et al. (2003) could show that granular materials such as quartz sand do not have constant frictional properties. Upon loading the granular materials undergo initially a limited elastic deformation, which is followed by strain hardening preceding failure at peak strength and subsequent strain softening until a stable strength value is reached (Fig. 4). The strain localisation at peak strength is associated with a material compaction-decompaction cycle as inferred from volumetric changes, with maximum dilation rates close to peak strength when faults form (Lohrmann et al., 2003). 
INSERT Fig. 4. Shear stress plotted versus shear strain for quartz sand (modified from Lohrmann et al., 2003; Panien et al., 2006). Strain softening from peak strength to stable strength correlates with dilation of sand.

The ring-shear tests for measuring internal friction and boundary friction differ in the design of the shear cell and lid. The setup for measuring internal friction ensures that shear displacement occurs entirely within the sand such that only intergranular deformation occurs, whereas the setup for measuring boundary friction ensures that deformation occurs between sand and a surface with controlled roughness, in our case a transparent and super polished self-adhesive foil (brand Alkor-Venilia, article nr. 120010; this foil has been renamed, and is now available as Gekkofix article nr. 11325 from Van Merksteijn Plastics B.V. in the Netherlands, www.gekkofix.nl).

The physical handling technique used to fill the annular cell of the ring-shear tester was identical to the one used to determine the bulk density and to the one prescribed in our thrust wedge experiments, i.e. material was sifted through a prescribed mesh sieve from c. $20 \mathrm{~cm}$ height into the shear cell at a filling rate of c. $250 \mathrm{ml} / \mathrm{min}$. Excess material was subsequently scraped off before assembling shear cell and shear lid.

Ring-shear measurements were performed at a shear velocity of $3 \mathrm{~mm} / \mathrm{min}$ for 4 minutes at a given normal load. For each test, measurements were done for different normal stresses ranging from c. $500 \mathrm{~Pa}$ to c. $2240 \mathrm{~Pa}$ in steps of c. $435 \mathrm{~Pa}$, and for each particular normal stress, peak strength and stable strength values were determined. Each ring-shear test was repeated three times for both quartz sand and corundum sand.

Measured shear stress values at peak strength and at stable strength are plotted against the applied normal stresses and a linear regression analysis is applied to the data, to obtain the friction coefficient, $\mu$, which corresponds to the slope of the line and the friction angle, $\phi$, which is $\tan ^{-1} \mu$. The cohesion is the linearly extrapolated value at zero normal stress. We report the range of friction angles and (apparent) cohesion values in Table 1.

\footnotetext{
INSERT Table 1. Range of mechanical properties of quartz and corundum sand obtained with a ring-shear tester. Values are rounded to nearest degree for friction angles and to nearest whole number for cohesion. $n$ is
} number of ring-shear tests at normal stresses ranging from c. 500 to 2240 Pa. 
407 The angle of internal friction at peak strength $\left(\phi_{p}\right)$ of the tested quartz and corundum sand are about $35-36^{\circ}$. The angles of internal friction at stable strength $\left(\phi_{\mathrm{s}}\right)$ are in both cases lower, with values around $30-31^{\circ}$. The angle of boundary friction $\left(\phi_{\mathrm{b}}\right)$ varies more for quartz sand on Alkor foil, with values between $15^{\circ}$ and $21^{\circ}$, than for corundum sand on Alkor foil with values of $24^{\circ} \pm 1^{\circ}$. At the range of applied normal stresses the cohesion at peak strength $\left(\mathrm{C}_{\mathrm{p}}\right)$

412 for both granular materials is in the order of a few tens of Pa. Boundary cohesion values $\left(\mathrm{C}_{\mathrm{b}}\right)$ 413 range from 14 to $141 \mathrm{~Pa}$ for quartz sand and from 23 to $44 \mathrm{~Pa}$ for corundum sand. The large spread in cohesion values is due to the linear extrapolation to zero normal stress on shear stress versus normal stress curves. Strain softening corresponds to the weakening of the shear zone after its formation. By comparing the mean values of the peak internal friction coefficient and the stable friction coefficient for each granular material, the mean strain softening can be determined, which amounts to c. $15-20 \%$ for both quartz and corundum sand.

Panien et al. (2006) used the same ring-shear tester at identical laboratory climatic conditions to determine the material properties of the same quartz and corundum sand as used in this model comparison. Their filling procedure (filling height and rate) is identical to ours, albeit with a slightly different sieve. The obtained values for repeated measurements correspond closely to ours. Their mean values for $\phi_{p}$ of quartz and corundum sand are $36^{\circ}$ and $37^{\circ}$, respectively and their mean values for $\phi_{\mathrm{s}}$ are $31^{\circ}$ and $32^{\circ}$, respectively. Using the same Alkor foil, Panien et al. (2006) also found that boundary friction angles at peak strength and at stable strength are lower for quartz sand than for corundum sand.

\subsubsection{Dilation and elasticity}

432

433 Deformation of the granular materials used in our experiments occurs by localization along 434 shear zones in combination with dilation. The dilation angles at peak strength for our dry quartz and corundum sand are difficult to determine with a ring-shear tester. It requires

436 measurements of the changes in volumetric strain, but the volumetric strain depends on the 437 width of the initial shear zone that forms. Assuming an initial shear zone width of about 10 
times the average grain size (Panien et al., 2006), we obtain very small dilation angles of less than $2^{\circ}$. Measurements of shear zone formation in dry sands indicate that dilation approaches zero once the shear zone has formed (Lohrmann et al., 2003; Bernard et al., 2007).

The elastic behaviour of the granular materials is characterized by at least two elastic parameters, e.g. Young's modulus E and Poisson's ratio v. Young's modulus is the ratio of uniaxial stress and strain: $\mathrm{E}=\sigma / \mathrm{e}$, while Poisson's ratio is the negative ratio of transverse strain $\left(e_{x}\right)$ to longitudinal strain $\left(e_{z}\right)$ under conditions of uniaxial stress, i.e. $v=-e_{x} / e_{z}$. Another elastic parameter is the bulk modulus $\mathrm{K}$ defined by the ratio of mean stress over volumetric strain. $\mathrm{K}$ is related to $\mathrm{E}$ and $v$ and can be expressed as $\mathrm{K}=\mathrm{E} /(3(1-2 v))$. Importantly, one has to differentiate between the elasticity of individual granular particles (which is in the order of tens of GPa for sand) and the elasticity of the bulk solid, i.e. the structure made by many grains in contact, which is generally much lower and the one relevant in our modelling approach.

The bulk moduli (K) of dry quartz and corundum sand were measured performing loadingunloading cycles (maximum load: $20 \mathrm{kPa}$ ) on sieved sand samples with a uniaxial confined compression tester at GFZ Potsdam. The values vary depending on the degree of compaction, which increases mainly during the first few loading-unloading cycles. Linear regression analysis of the stress-strain curves (up to a strain of 0.00003 ) during loading of the first ten cycles suggests an effective bulk modulus of around $200 \mathrm{MPa}$ for both sands under laboratory conditions. Assuming a Poisson's ratio, $v$, of about 0.25 results in a Young's modulus E of $300 \mathrm{MPa}$. Though orders of magnitude smaller than for single grains these values are so high that elastic deformation in the experiments is expected to be below the detection threshhold of even sophisticated optical strain measurement systems (e.g. microns when applying subpixelresolution particle image velocimetry, Adam et al., 2005). Stress is therefore expected to accumulate and relax without obvious deformation in sandbox experiments. This is in contrast to more elastic modelling approaches where proper scaling of elasticity from nature to the analogue model yields observable elastic effects (Rosenau et al., 2009).

\subsection{Brittle thrust wedges}


The formation of fold-and-thrust belts and accretionary wedges in compressional settings is comparable to the process of forming a wedge of snow in front of a moving bulldozer with a taper angle described by the critical taper theory (e.g. Davis et al., 1983; Dahlen et al., 1984; Zhao et al., 1986; see Buiter et al., 2012 for an extensive review of brittle compressional wedge models). The material being pushed will reach an equilibrium angle, the so-called critical taper angle, which is the sum of the surface slope angle $(\alpha)$ and the basal dip angle of the wedge $(\beta)$. The critical taper angle depends on the material properties within the wedge, the pore fluid pressure and the strength of the decollement along the base of the wedge.

Under the assumption that the material deforms according to the Coulomb failure criterion and that the base of the wedge is cohesionless (i.e., $C_{b}=0$ ), the critical taper theory permits the derivation of the critical taper angle for a dry sand wedge (pore fluid pressure is zero) knowing the angle of internal friction, the internal cohesion and the angle of basal friction (Fig. 5). Dahlen et al. (1984) show that a cohesionless wedge results in a perfectly triangular form, whereas a wedge with a constant internal cohesion will acquire a concave upward surface.

Fig. 5 shows wedge stability fields for cohesionless and internal cohesive sands with frictional properties that closely correspond to those obtained from ring-shear tests on our sands: for a cohesionless sand at peak strength and at stable strength, and for a cohesive sand at peak strength with depth-dependent internal cohesion (Buiter et al., 2016).

INSERT Fig. 5. Zoom of critical taper curves for cohesionless sand at peak strength $\left(\phi_{p}=36^{\circ}, \phi_{b}=15^{\circ}\right.$ and $C=$ $0 P a)$, cohesionless sand at stable strength $\left(\phi_{s}=31^{\circ}, \phi_{b}=15^{\circ}\right.$ and $\left.C=0 P a\right)$, and a cohesive sand at peak strength with depth-dependent cohesion $\left(\phi_{p}=36^{\circ}, \phi_{b}=15^{\circ}\right.$ and $C=20 \mathrm{~Pa} \mathrm{~cm}^{-1}$ times $z$, with $z=$ depth, following Zhao et al. (1986)).

Wedges in the stable field will slide stably without internal deformation as long as no new material is accreted. This is our experiment 1 , which has an initial wedge shape with a horizontal base and a $20^{\circ}$ surface slope (Fig. 5). Unstable, subcritical wedges will deform internally upon compression towards the critical taper angle. Our experiment 2 and 3 models with initial horizontal layering start out as subcritical wedges (Fig. 5). 


\subsection{General model building procedure}

506

507

\subsection{Model analysis} hereafter termed shortening.

Although each lab used its own experimental apparatus, all labs applied the same type of selfadhesive Alkor foil to cover the base and the four vertical walls of their experimental apparatus in order to guarantee identical shear stresses at the boundaries. In addition, each lab received a detailed document outlining the prescribed model-building techniques including details on mesh sieve structure for model construction and leveling techniques (Appendix A). The model was built by sifting sand through a sieve with specified mesh sieve from a height of $20 \mathrm{~cm}$ at a filling rate of c. $250 \mathrm{ml} / \mathrm{min}$. This procedure is identical to the one used to fill the test cell during ring-shear test measurements. The minimum width of the model (measured along the mobile wall) was prescribed at $20 \mathrm{~cm}$. Model widths as well as laboratory temperature and relative humidity are shown in Table 2.

INSERT Table 2. Overview of laboratory climatic conditions and model widths. Most laboratories performed experiments 2 and 3 twice, and range of values for room temperature and relative humidity are indicated. Exceptions to the prescribed modeling procedure are also given.

We analyse our models in a qualitatitave way by comparing cross-sectional views and top views and in a quantitative way by cross section measurements. As boundary stresses created significant drag of structures along the sidewalls, our visual comparison is done for sections away from the sidewalls. Consequently, for models analysed in a conventional way by physically cutting the model, we only show cross sections through the final stage of deformation. However, for models analysed by X-ray computed tomography (XRCT) we show the cross-sectional evolution at successive increments of mobile wall displacement,

Our quantitative analysis consisted of measuring surface slope (Fig. 6a), thrust spacing between forward thrusts (Fig. 6b), dip angle of newly formed forward thrusts at base, mid and top (Fig. 6c), thrust initiation (i.e. at how much shortening a particular thrust forms) and number of thrusts at the end of the experiment. We define a thrust as formed when it shows a 
small, visible offset in cross section. As in the previous model comparison (Schreurs et al., 2006), two of us (Guido Schreurs and Susanne Buiter) performed the quantitative analysis by measuring the aforementioned parameters in the same manner and averaging the obtained values. In general the differences between the two measurers were small, with average difference in slope values of $1-2^{\circ}$ and maximum difference in dip values of $3^{\circ}$. Also differences in measured distance values were generally small. In models analysed by XRCT all parameters were measured using cross-sectional images taken at $0.5 \mathrm{~cm}$ increments of displacement for Experiment 1, and at $0.2 \mathrm{~cm}$ increments of displacement until $1 \mathrm{~cm}$ and subsequently at $0.5 \mathrm{~cm}$ increments until $10 \mathrm{~cm}$ shortening for Experiments 2 and 3.

INSERT Fig. 6. Schematic illustration of measurements of a) surface slope, b) forward thrust spacing, and c) thrust dip angles. Surface slope is measured as the best fitting line through the valleys (Stockmal et al., 2007) and can only be determined once at least 2 thrusts have formed. Thrust spacing is measured horizontally from a newly initiated in-sequence forward thrust to the previously formed forward thrust.

To document lateral variations of structures, we compared sections at five different positions. As model width varied between laboratories, we defined the five sections in terms of alongstrike model width at 25\%,50\% - $2 \mathrm{~cm}, 50 \%, 50 \%+2 \mathrm{~cm}$, and $75 \%$ positions (see Fig. 7 ).

INSERT Fig. 7. Top view photograph illustrating position of cross sections at $25 \%$ (1), $50 \%-2 \mathrm{~cm}$ (2), $50 \%$ (3), $50 \%+2 \mathrm{~cm}$ (4), and $75 \%$ (5) of model width (measured parallel to mobile wall, which moves here from bottom to top). Model width is $80 \mathrm{~cm}$ in this particular experiment.

\section{Experiment 1}

\subsection{Experiment 1: Model set-up}

571 In the first experimental set-up, a quartz sand wedge with a horizontal base $\left(\beta=0^{\circ}\right)$ and a 572 surface slope $(\alpha)$ of c. $20^{\circ}$ was constructed adjacent to the mobile wall (Fig. 8). The height of 573 the wedge immediately adjacent to the mobile wall is $3 \mathrm{~cm}$. 
INSERT Fig. 8. Model set-up for experiment 1.

577

578

579

580

581

582

583

584

585

586

587

588

589

590

591

592

593

594

595

596

597

598

599

600

601

602

603

604

605

606

607

Model building consisted of two steps (Fig. 9). In a first step quartz sand was sieved in the sandbox partly sloping towards the fixed wall (Fig. 9a). In a second step a template with a $20^{\circ}$ slope-angle was attached onto each sidewall and excess material was scraped towards the tip of the wedge and taken out (Fig. 9b). Adjacent to the fixed wall, there was at least $5 \mathrm{~cm}$ space where no sand covered the base. The model was shortened $4 \mathrm{~cm}$ by inward movement of the mobile wall. Eleven analogue modeling laboratories ran experiment 1 once.

INSERT Fig. 9. Model building procedure for experiment 1 shown in cross section. A template with the shape of the final wedge is attached on top of each sidewall to guide the scraper (see Appendix A-2). Stippled line indicates sand wedge before final scraping.

\subsection{Experiment 1: Results}

Three intrinsic material parameters are important in the critical taper theory: the internal peak friction, internal cohesion, and basal friction. Of these three parameters, the basal friction of quartz sand is the least constrained, varying between 15 and $21^{\circ}$ (Table 1). However, even when taking into account this uncertainty, the quartz sand wedge of experiment 1 is well within the stable domain. Hence, the wedge should slide stably without internal deformation and consequently the surface slope should remain constant throughout the experiment.

All experiment 1 models do conform to the critical taper theory and are stable. The quartz sand wedge is translated along the horizontal base and is not affected by internal localized deformation. Apart from a slight slope change in the extreme front region of the wedge in a number of experiments, the overall surface slope remains constant (Fig. 10 and 11). 
608

609

610 INSERT Fig. 10. Evolution of experiment 1 model run at Bern after 0, 2 and $4 \mathrm{~cm}$ of shortening (a) XRCT 611 sections through centre of model, (b) top view photographs of model.

612

613

614 INSERT Fig. 11. Cross sections through centre of experiment 1 models after $4 \mathrm{~cm}$ of shortening. Sections of 615 Bern,GFZ@Bern, and IFP are XRCT images. Note that Toronto and Uppsala laboratories added extra sand on 616 the wedge before cutting cross section.

617 


\section{Experiment 2}

623 In experiment 2 alternating horizontal layers of quartz and corundum sand are shortened by 624 inward movement of a mobile wall (Fig. 12). Both the base and the surface of the model are 625 horizontal $\left(\alpha=\beta=0^{\circ}\right)$ and the "wedge" starts in the unstable field (Fig. 5). The minimum 626 length of the undeformed model, measured parallel to the movement direction of the mobile 627 wall, was $35 \mathrm{~cm}$. The model had an initial thickness of $3 \mathrm{~cm}$ and directly overlies the base of 628 the model. Total shortening of the model by inward displacement of the mobile wall was 10 $\mathrm{cm}$. No exit slot existed below the mobile vertical wall and the base of the model.

INSERT Fig. 12. Model set-up for experiment 2.

Fourteen laboratories participated in experiment 2, running a total of 25 models, of which five were analysed by XRCT.

\subsection{Experiment 2: Results}

639

\subsubsection{Evolution of models analysed by XRCT}

Fig. 13 shows the cross-sectional evolution through the centre of five thrust wedge models analysed by XRCT after 1, 2, 6 and $10 \mathrm{~cm}$ of shortening. Movies showing additional stages in 644 the cross-sectional evolution are given in the journal's repository. Shortening is 645 accommodated by forward thrusts, which propagate in-sequence towards the foreland, and by 646 back thrusts.

648 The first pop-up structure develops between 0.5 and $1 \mathrm{~cm}$ of shortening (Fig. 14) adjacent to 649 the mobile wall. The dip of the first forward thrust steepens slightly upwards, with dips 650 varying between $22^{\circ}$ and $25^{\circ}$ at the bottom, between $27^{\circ}$ and $31^{\circ}$ at the middle, and between $65126^{\circ}$ and $32^{\circ}$ at the top (Fig. 15a). The back thrust of the first pop-up strucure generally dips 
652 steeper than the forward thrust, in particular near the base of the model. The variation in dip 653 of the first-formed back thrust is large, with dip angles between $26^{\circ}$ and $46^{\circ}$ at the bottom, 654 and between $27^{\circ}$ and $45^{\circ}$ at the middle and at the top (Fig. 15b). The width of the pop-up at 655 the surface varies because of the considerable variation in dip of the back thrust. Models with 656 a steep back thrust (Bern 2B and IFP 2A) have a narrower pop-up width than models with a 657 shallow-dipping back thrust (Fig. 13; $1 \mathrm{~cm}$ of shortening).

658

659 After $2 \mathrm{~cm}$ of shortening a second back thrust has formed in all models, except in model Bern 660 2A. The first-formed forward thrust takes up most of the initial shortening and the first661 formed back thrust is displaced along it (Fig. 13;2 cm of shortening). A second in-sequence 662 forward thrust forms between 3 and $5.5 \mathrm{~cm}$ of shortening and further in-sequence forward 663 thrusts develop with progressive shortening. The spacing to the previously formed forward 664 thrust at the moment of initiation of a new forward thrust tends to increase for subsequent 665 thrusts (Fig. 14b). In general the dip of newly formed in-sequence thrusts near the base of the 666 model becomes shallower with progressive deformation

667

668 A second pop-up structure forms in all XRCT models, albeit at different stages: at $5.5 \mathrm{~cm}$ of 669 shortening for Bern 2A, at $6.5 \mathrm{~cm}$ for GFZ@Bern, and at $9 \mathrm{~cm}$ for Bern 2B, IFP 2A and IFP 670 2B. Back thrusts associated with this second pop-up generally cross-cut earlier-formed, now 671 inactive forward thrusts.

672

673

674

675

INSERT Fig. 13. Cross-sectional evolution through centre of experiment 2 models after 1, 2, 6 and $10 \mathrm{~cm}$ of 676

677 The surface slope evolution of the wedge for models analysed by XRCT is shown in Fig. 16 678 Oscillations in surface slope angles reflect the formation of new thrusts. All models except 679 Bern 2A show these oscillations. The Bern 2A model shows instead a steady increase in 680 surface slope.

681

682

683

684 

at which a forward thrust forms at centre of model. (b) Spacing to previously formed forward thrust at the moment of initiation of a new, in-sequence forward thrust.

INSERT Fig. 15. Dip angles of successive in-sequence forward (a) and back thrusts (b) in centre of experiment 2 XRCT models, measured at top, middle and bottom.

INSERT Fig. 16. Surface slope evolution at centre of experiment 2 XRCT models. Only values that could be reliably measured in XRCT images are given.

696

\subsubsection{Final deformation stage}

698

Cross sections through the centre of all experiment 2 models after $10 \mathrm{~cm}$ of shortening show a series of forward and back thrusts directly adjacent to the mobile wall (Fig. 17). In addition, most models show a second pop-up structure that formed in front. However, the models of Kyoto, Parma, Piscataway 2A and 2B, and Stanford 2A lack this second pop-up structure and consequently have higher surface slopes.

704

705

INSERT Fig. 17. Cross sections through centre of experiment 2 models after $10 \mathrm{~cm}$ of shortening. Width of each panel shown is $25 \mathrm{~cm}$. Note that some labs added a layer of sand before cutting the model. Cross sections from Lille $2 A$ and $2 B$ are at $50 \%$ - $2 \mathrm{~cm}$ position. Image quality of cross sections from Stanford $2 A$ and $2 B$ was not good enough for reproduction.

The top views for experiment 2 after $10 \mathrm{~cm}$ shortening are shown in Fig. 18. Approaching the sidewalls of the models, thrusts are convex to the hinterland with the thrust wedge becoming narrower and steeper. Along-strike structural changes are present in all models away from the

714 sidewalls, with curved thrust segments and along-strike merging of thrusts. The along-strike 715 changes are also well visible in the cross-sectional wedge geometries shown for 5 different 716 locations in Fig. 19.

718 The surface slope is measured in cross sections at the $25 \%, 50 \%$ and $75 \%$ positions and varies 719 between $4^{\circ}$ and $24^{\circ}$ (Fig. 20). Surface slopes measured along one sidewall ( $0 \%$ position) are 
shown for comparison and are, for one particular model, generally considerably higher than those measured at the other three positions. Variations in surface slope along strike within one model are generally small, with most models showing along-strike differences between maximum and minimum surface slope of less than $4^{\circ}$ (Fig. 20). Only the Lille $2 \mathrm{~B}$ model and Melbourne 2A model have higher along-strike differences of $6^{\circ}$ and $11^{\circ}$, respectively.

The number of thrusts has also been measured at the $25 \%, 50 \%$ and $75 \%$ positions (Fig. 21 ). Models have between 3 and 5 forward thrusts at the end of the experimental run $(10 \mathrm{~cm}$ of shortening), except Mexico 2A and 2B, and Piscataway 2A, which have a higher number of thrusts (up to 9), and Bern, which has only two forward thrusts (Fig. 21a). The number of backthrusts varies between 1 and 9 , and in comparison with the forward thrusts, there is an overall higher along-strike variability in the number of backthrusts within one particular model.

INSERT Fig. 18. Top views of experiment 2 models after $10 \mathrm{~cm}$ of shortening showing along-strike structural variability. Movement of mobile wall is from bottom to top Note that Lille $2 A$ and $2 B$ models have a grid of corundum sand imprinted on the surface, whereas Mexico $2 A$ and $2 B$ models used prescribed sand mixed with dark sand particles. All photos are shown at the same scale, given in the top left photo.

INSERT Fig. 19. Cross sections after $10 \mathrm{~cm}$ shortening for experiment 2 models at positions 25\%, 50\%-2 cm, $50 \%, 50 \%+2 \mathrm{~cm}$ and $75 \%$ (see Fig. 6) showing along-strike structural variability. Note that some laboratories added a post-kinematic sand layer before wetting and sectioning.

INSERT Fig. 20. Surface slope after $10 \mathrm{~cm}$ of shortening at 25\%, 50\% and 75\% positions for experiment 2 models. The surface slope could not be reliably measured on all cross-sectional images. Surface slopes for Lille $2 A$ and Lille $2 B$ models were measured at 50\%-2cm position. Numbers above symbols indicate difference between maximum and minimum slope angle within one particular model and are only given for those models in which the surface slope could be determined at all three positions. Surface slope values along one sidewall (0\% position) are given for comparison and are generally higher.

INSERT Fig. 21. Number of forward and back thrusts at 25\%, 50\% and 75\% position after $10 \mathrm{~cm}$ of shortening for experiment 2 models. Numbers above symbols indicate along-strike differences in number of thrusts and are only given for those models, in which thrusts could be reliably determined at all three positions. 
4.2.3. Model similarities and variability

The experiment 2 models share a number of similarities:

(1) the development of forward thrusts propagating in-sequence and the formation of back 763 thrusts,

764 (2) the formation of a first pop-up adjacent to the mobile wall forming in all models before 1 $765 \mathrm{~cm}$ of shortening

766 (3) the fairly uniform dip of the first forward thrust, which steepens slightly upwards, 767 resulting in a slightly listric thrust plane

768 (4) the first backthrust that forms close to the mobile backwall dips steeper than the first 769 forward thrust

770 (5) in top views thrust wedges are curved with a convex to the hinterland shape. Sidewall 771 friction results in a narrower and steeper wedge immediately along the sidewall when 772 compared to sections through the center of the model

774 However, our quantification of experiment 2 model results shows that there are also important 775 variations, notably:

(1) The number of forward thrusts and backthrusts that formed after a certain amount of shortening is variable when comparing all models (Fig. 14a). For example, the number of forward thrusts through the centre of the model after $10 \mathrm{~cm}$ shortening varies between 2 and 9, wheras the number of back thrusts varies between 1 and 9 (Fig. 21). Variability in the number of thrusts within one particular model is less with a difference in number of thrusts 782 along strike varying from 0 to 3 (Fig. 21).

783 (2) The surface slope of the thrust wedge is highly variable. Whereas four out of the five models analysed by XRCT show an oscillating behaviour in surface slope, reflecting new thrust formation, Bern 2A model shows a steady increase in surface slope. After $10 \mathrm{~cm}$ of shortening the surface slope through the centre (50\% position) of all models varies between $4^{\circ}$ and $24^{\circ}$.

788 (3) Not all models develop a second pop-up structure. In case a second pop-up forms, the associated back-thrusts cut in most cases previously formed forward thrusts in the hinterland. 
791 The variations in overall wedge geometry result from local scale variations in thrust dips.

792 Notably, the variability in dip of newly formed back thrusts is large, with dip angles ranging 793 from $26^{\circ}$ to $50^{\circ}$, and also the width of the initial pop-up structure through the centre of the 794 models (Fig. 13) varies considerably due to varying dip angles of forward and in particular 795 back thrusts.

796

797

798

799

800

801

802

803

804

805

806

807

808

809

810

811

812

813

814

815

816

817

818

819

820

821

822

\subsection{Experiment 2 model and the critical taper theory}

The internal peak friction angles of the quartz and corundum sand used in experiment 2 are nearly identical (Table 1) and a value of $\phi_{\mathrm{p}}=36^{\circ}$ is considered a good approximation for the entire sand wedge. If we take into account the uncertainty in the basal friction angle $\left(\phi_{\mathrm{b}}\right)$ of the quartz sand layer, ranging between $15^{\circ}$ to $21^{\circ}$, the analytical solutions derived from the critical taper theory indicate that the critical taper angle, which equals the surface slope for experiment 2 with a horizontal base, would be between c. 4 and $6^{\circ}$ (taking only the lowest of the two permissible critical taper angles) for a sand wedge with depth-dependent cohesion of $20 \mathrm{~Pa} \mathrm{~cm}^{-1}$.

The initial horizontally layered models of experiment 2 start out as a sub-critical wedge and deform by in-sequence thrusting. After $10 \mathrm{~cm}$ of shortening sections through the centre of the models show a wide spread in surface slope, ranging between $4^{\circ}$ and $24^{\circ}$. Only the surface slopes of models GFZ@Bern, Taipei 2A, Uppsala 2B, with slopes of $5^{\circ}, 6^{\circ}$, and $4^{\circ}$, respectively, are within the predicted range of values for a cohesionless wedge. The fact that a few models do reach a critical taper could suggest that at $10 \mathrm{~cm}$ shortening the wedges are at the verge of transition from an immature, subcritical wedge to a critical one.

The discrepancy between most model surface slopes and analytical predictions of the critical taper theory are possibly related to a combination of factors described below:

(1) After $10 \mathrm{~cm}$ shortening, the surface slope in the deforming thrust wedge might not have yet stabilised and more shortening might be needed in order for the sand wedge to achive steady state and reach its critical taper. It has also to be kept in mind that the 
critical taper theory assumes a perfect, infinite length wedge, with a sharp tip. Here, the wedge tip is replaced by a flat layer of thickness $(3 \mathrm{~cm})$, which is as much as half the maximum wedge height (about $6 \mathrm{~cm}$ ) at the end of experiments. Departures from the assumptions of the theory are therefore substantial.

(2) Compaction and dilation of sand during localization of deformation along faults, which is not considered in the critical taper theory, also affects the frictional strength of the wedge. Lohrmann et al. (2003) show that the frictional strength of the wedge changes as faults form in the wedge, and that the behaviour of the wedge is controlled by the frictional strength of these faults, which have angles of stable sliding. Hence, in our case it would be more appropriate to take the internal angle of friction at stable sliding strength $\left(\phi_{\mathrm{s}}\right)$ which is $31^{\circ}$, instead of the internal angle of friction at peak strength $\left(\phi_{\mathrm{p}}\right)$, which is c. $36^{\circ}$, and also the boundary friction angle at stable sliding strength of quartz sand ( $\left.\phi_{\mathrm{bs}}\right)$, which is between 9 and $14^{\circ}$ instead of the boundary friction angle at peak strength $\left(\phi_{\mathrm{b}}\right)$, which is between 15 and $21^{\circ}$ (Table 1). Using stable sliding internal friction values (neglecting cohesion), the critical surface slopes range between $3^{\circ}$ and $5.2^{\circ}$, i.e. essentially the same as using the peak values $\left(3^{\circ}\right.$ to $\left.6^{\circ}\right)$, because the loss of strength in the bulk material and at the base partly counteract each other.

(3) Ring-shear tests show that our analog model materials have a basal cohesion that is not taken into account in the critical taper theory. With uniform basal and peak cohesion, a critical taper would assume a concave surface shape. Estimates using the limit analysis method (Mary et al., 2013b) yield surface slopes around $5^{\circ}$ to $6^{\circ}$ for $\phi_{p}=$ $36^{\circ}, \phi_{\mathrm{b}}=15^{\circ}, \mathrm{C}_{\mathrm{p}}=20 \mathrm{~Pa}$ and $\mathrm{C}_{\mathrm{b}}=15 \mathrm{~Pa}$; and in a higher range of $11^{\circ}$ to $13^{\circ}$ for $\phi_{\mathrm{p}}$ $=36^{\circ}, \phi_{\mathrm{b}}=21^{\circ}, \mathrm{C}_{\mathrm{p}}=70 \mathrm{~Pa}$ and $\mathrm{C}_{\mathrm{b}}=140 \mathrm{~Pa}$. Therefore, cohesion of the materials could in part explain the discrepancy with the critical taper theory.

\section{Experiment 3}

\subsection{Experiment 3: Model set-up}


856 In the set-up of experiment 3 a thin rigid sheet, $1 \mathrm{~mm}$ thick, and $12 \mathrm{~cm}$ in length is attached to 857 the mobile wall and underlies part of the model. The tip of the rigid sheet has a perpendicular 858 cut. Displacement of the mobile wall creates a moving basal velocity discontinuity where 859 deformation localizes away from the mobile wall during shortening of the model (Fig. 22). 860 The thin sheet is covered by Alkor foil, as are the base and the four vertical walls of the 861 experimental apparatus. The model consists of three 1-cm-thick layers of quartz and 862 corundum sand. Minimum prescribed model length parallel to the movement direction is 35 $863 \mathrm{~cm}$

864

INSERT Fig. 22. Model setup for experiment 3.

866

867 Experiment 3 was done by 14 laboratories, and a total of 22 models were run, of which five 868 were analysed by XRCT.

\subsection{Experiment 3: Results}

\subsubsection{Evolution of models analysed by XRCT}

875 The cross-sectional evolution through the centre of experiment 3 models reveals that in all 876 five models analysed by XRCT a pop-up structure has formed at the tip of the moving basal 877 sheet after $1 \mathrm{~cm}$ of shortening (Fig. 23). At this stage the overall dip of the backthrust is 878 somewhat steeper than the forward thrust (Fig. 24). Both forward thrust and backthrust have a 879 slightly listric shape with dips between $26^{\circ}$ and $32^{\circ}$ at the top, and between $17^{\circ}$ and $23^{\circ}$ near 880 the base (Fig. 25).

882 With continuing shortening the first-formed forward thrust is advected upward along the 883 backthrust, and new in-sequence forward thrusts initiate at the base, propagate upward and 884 either merge with the pre-existing forward thrust at depth or reach all the way to the surface. 885 This process is repeated during continuing shortening: previously formed forward thrusts are 886 displaced along the backthrust and new in-sequence forward thrusts form in the footwall. The 887 dip of new in-sequence forward thrusts is in general shallower than the first-formed forward thrust and their dip near the surface varies between $22^{\circ}$ and $27^{\circ}$. 
INSERT Fig. 24. Dip of successive forward thrusts at time of initiation through centre of model, measured at

INSERT Fig. 25. Evolution of surface slope through centre of experiment 3 XRCT models. The lines connecting measurements illustrate the oscillating behaviour of the surface slope, which tends to become less with increasing shortening. Numbers above symbols indicate the difference in maximum and minimum surface slope between the five models at a specific shortening increment.

902

After $3.5 \mathrm{~cm}$ of shortening, the surface slope of the five XRCT models, measured in sections through the centre of the model, varies between $5^{\circ}$ and $16^{\circ}$ (Fig. 25). During initial shortening the surface slope in each model increases, and then shows an oscillating behaviour which tends to become less important with increasing shortening. Comparing the XRCT models indicates that the spread in surface slope values tends to diminish with increasing shortening. At $10 \mathrm{~cm}$ of shortening surface slopes range between $16^{\circ}$ and $22^{\circ}$ (Fig. 25).

909

\subsubsection{Final deformation stage}

A comparison of all cross sections at the $50 \%$ position after $10 \mathrm{~cm}$ shortening (Fig. 26) shows

913 very similar geometries: a series of forward thrusts with relatively small, individual offsets,

914 and one backthrust with a large offset, except for the Lille and Melbourne 3A models which 915 show an additional backthrust.

917 Top views of all models indicate slight lateral variations in the strike of forward thrusts and 918 lateral merging of forward thrusts (Fig. 27). In top views, both forward thrusts and 919 backthrusts have a convex to the hinterland shape as a result of friction along the sidewalls.

921 Cross sections at five different positions after $10 \mathrm{~cm}$ of shortening (Fig. 28) show minor 922 lateral variations, which mainly relate to surface slope and number of forward thrusts. 
924 The surface slope for all models at the $25 \%, 50 \%$ and $75 \%$ positions is quite uniform, with 925 values between $16^{\circ}$ and $24^{\circ}$ (Fig. 29). The Uppsala $2 \mathrm{~B}$ model is the only exception. It has a 926 shallower surface slope ranging between $12^{\circ}$ and $14^{\circ}$ at all three positions. Lateral differences 927 in surface slope within one model are minor, mostly only between 1 and $3^{\circ}$. Only the Bern $3 \mathrm{~B}$ 928 and Lille models show larger along-strike variations with differences in values of surface 929 slope up to $5^{\circ}$.

930

931 The number of forward thrusts was determined in cross sections at the $25 \%, 50 \%$ and $75 \%$ 932 positions and only thrusts that produced a noticeable offset at the surface were considered 933 (Fig. 30). The number of forward thrusts varied between 4 and 9 among all models. Within 934 one particular model the difference in thrust number along strike is small, between 1 and 2 for 935 most models, with only the Bern 3B, GFZ@Bern and Piscataway 3A models showing a 936 difference in thrust number of 3.

INSERT Fig. 26. Cross sections after $10 \mathrm{~cm}$ of shortening through centre of experiment 3 models. Cross section of Stanford $3 A$ is not shown, because image quality was insufficient for reproduction.

INSERT Fig. 27. Top views after $10 \mathrm{~cm}$ of shortening for experiment 3 models. Lille model has a surface grid of corundum sand.

INSERT Fig. 28. Cross sections after $10 \mathrm{~cm}$ shortening for experiment 3 models at positions $25 \%, 50 \%-2 \mathrm{~cm}$, $50 \%, 50 \%+2 \mathrm{~cm}$ and $75 \%$ of model width (see Fig. 7).

INSERT Fig. 29. Surface slope after $10 \mathrm{~cm}$ of shortening at $25 \%, 50 \%$ and $75 \%$ position for experiment 3 models experimental 3 models. Note that only those thrusts were considered that produced a noticeable offset at the surface. The number of thrusts in Stanford $3 A$ and $3 B$ models could not be reliably determined due to poor 
964 Visual comparison of all experiment 3 models shows that the evolution of structures both in 965 cross section and top view is very similar. A pop-up structure forms initially above the 966 moving basal velocity discontinuity, with subsequent in-sequence forward thrusts being advected along the backthrust and becoming sucessively inactive when a new forward thrusts forms at the tip of the moving basal sheet. The backthrust, however, remains active throughout the shortening and accommodates much more fault displacement than individual forward thrusts. Nearly all models have only one backthrust and between 4 and 9 forward 971 thrusts.

The surface slope of the models at $10 \mathrm{~cm}$ shortening varies between 12 and $24^{\circ}$. These values are well above the predicted critical taper angles (c. 4- $6^{\circ}$ ) for sand with $\phi_{\mathrm{p}}=36^{\circ}$, $\phi_{\mathrm{b}}$ between $15^{\circ}$ and $21^{\circ}$ and $\mathrm{C}=0$. However, the particular set-up of experiment 3 probably does not warrant a direct comparison with the critical taper theory. The critical taper theory accounts for a situation in which the velocity discontinuity (between mobile wall and material) is adjacent to the wedge, whereas in experiment 3 the velocity discontinuity is below the sand wedge. The pop-up that forms at the tip of the rigid basal sheet results in a wedge of material in the footwall of the backthrust that remains undeformed and is passively displaced along with the basal sheet. As a result the backthrust remains active throughout the experiment, advecting material and forward thrusts upward, but at the same time preventing propagation of forward thrusts away from the velocity discontinuity towards the foreland.

\section{Discussion of model results}

\subsection{The effect of sidewall friction}

990 Sidewall friction in sandbox models has an influence on thrust wedge geometry (e.g. Costa

991 and Vendeville, 2004; Schreurs et al., 2006; Souloumiac et al., 2012). Thrust wedges are 992 generally narrower and steeper near the sidewalls and shallower and wider in the centre of the 
model. This is caused by sidewall drag causing rotation of the stress field within the sand.. In our models with fixed sidewalls and a mobile backstop, the lateral effects due to sidewall friction result in a convex-to-the-backstop shape of the thrust wedge in top view. This is largely consistent with the analysis of Souloumiac et al. (2012), who measured the effect of sidewall friction in experiments in which a sand wedge undergoes plane-strain shortening. They varied the surface $S_{L}$ of sand in contact with the sidewalls, and the surface $S_{B}$ in contact with the base plate of the sandbox. For initial ratios $\mathrm{S}_{\mathrm{L}} / \mathrm{S}_{\mathrm{B}}$ between 0.1 and 0.35 , Souloumiac et al. (2012) found that sidewall friction during shortening of the sand wedge causes thrust curvature near the side walls, whereas for $\mathrm{S}_{\mathrm{L}} / \mathrm{S}_{\mathrm{B}}$ ratios $<0.1$ sidewall friction has negligible effects. At $\mathrm{S}_{\mathrm{L}} / \mathrm{S}_{\mathrm{B}}$ ratios $>0.35$, thrusting occurs at different locations throughout the box, revealing a major experimental bias (Souloumiac et al., 2012). For the experiment 2 and 3 models presented here, $\mathrm{S}_{\mathrm{L}} / \mathrm{S}_{\mathrm{B}}$ varies between 0.075 and 0.3 , and all models show thrust curvature near the sidewalls (Figs. 18 and 29). The fact that the Bern and IFP models, with $\mathrm{S}_{\mathrm{L}} / \mathrm{S}_{\mathrm{B}}$ ratios $<0.1$ still show thrust curvature near the sidewalls might be related to the difference in the nature of the walls, i.e. foil-covered walls in the experiments presented here and glass walls in the experiments of Souloumiac et al. (2012). From an inspection of top views, we estimate that sidewall friction only plays a role on thrust wedge curvature until c. 5 $\mathrm{cm}$ away from the sidewalls. All our quantified parameters are measured in sections that are at least $5 \mathrm{~cm}$ away from the sidewalls (except IFP exp 1), and hence our results are not expected to be affected by the effects of sidewall friction.

Friction on the moving back wall also has an effect. In the previous analogue model comparison (Schreurs et al., 2006, Fig. 2b), six models developed a pop-up against the back wall, and two models developed a single forward thrust rooted at the back wall-base plate corner. Souloumiac et al. (2010, Fig. 11 and 14) showed that this difference is due to the friction on the back wall: at high friction, a pop-up develops in order to reduce sliding on the back wall, whereas at low friction we observe a single forward thrust and vertical slip on the back wall. Here, sands and sidewall materials are identical in all models, and all models develop the same initial structure: a pop-up. This is a substantial improvement compared to the previous comparison (Schreurs et al., 2006), and a confirmation that the pop-up / forward thrust discrepancy is due to differences in friction of sand against the back wall material, provided other parameters like basal friction are fixed. 
The results of our three different thrust experiments demonstrate that the set-up itself has an influence on model reproducibility with experiment 1 showing the highest degree of similarity, followed by experiment 3 and then by experiment 2 .

All experiment 1 models show exactly the same evolution, i.e. stable sliding of a triangular sand wedge without significant internal deformation and a surface slope that remains nearly constant throughout the experiment. Experiments 2 and 3 consist of horizontally layered models that are shortened by inward movement of a mobile wall. The undeformed models in both experiments represent subcritical wedges. The only difference between the two experimental setups is the presence of a thin, rigid basal sheet attached to the mobile wall in experiment 3 . Hence, in experiment 3 a singularity is stationary with respect to the moving sheet tip and displacement of the mobile wall forces deformation to remain localized at the singularity resulting in a good similarity among all models with only minor variations in quantitative parameters such as surface slope, and thrust dip. In contrast, in experiment 2 , the singularity is located at the active forward thrust, which is less constrained in space, and consequently models show a larger variability, in particular with regard to the number of forward thrusts, which in experiment 2 varies from 2 to 9 for forward thrusts and from 1 to 9 for backthrusts.

\subsection{Variations within and between models}

Both experiments 2 and 3 models show similar cross-sectional evolutions demonstrating reproducibility of first-order experimental results. However, for both experiments we do observe variations of structures both in map view and in cross sections. Thrusts merge along strike and show slight variations in their surface strike. Quantification of parameters in crosssections also documents variations among models and lateral variations within one model, in particular for experiment 2. Possible explanations for these variations are discussed below:

(1) Even though the prescribed model construction techniques were stringent concerning sieve mesh size, sifting height, and sifting rate, it is unlikely in practice that the initial undeformed model is perfectly homogeneous and has constant values of internal 
friction, basal friction, internal cohesion and basal cohesion throughout. Slight variations in these values might be caused by small changes in sifting height or sifting rate during model construction or might have occurred during off-scraping of excess material. An inspection of the first-formed pop-up structure in the centre of XRCT experiment 2 models shows that those of Bern 2B and IFP 2A are quite asymmetric, with a steep backthrust dipping at c. $45^{\circ}$ and a relatively shallow forward thrust. The other three models (Bern 2A, GFZ@Bern, and IFP 2B) have a more symmetric pop-up structure. Analogue models testing the influence of basal friction on the thrust wedge shape (e.g. Colletta et al., 1991; Huiqi et al., 1992) reveal that initially horizontally layered models with a low basal friction have a more symmetric style of thrusting than models with a high basal friction, which have a more asymmetric thrust style. This would suggest a variability in initial basal friction between the models, at least near the moving wall with models Bern 2B and IFP 2A having higher values of basal friction. This variability, as well as the variability of the measured friction of sand on Alkor foil in ring-shear tests (boundary friction, Table 1), could be due to repeated use of the Alkor foil, which would thus change (probably increase) basal frictional properties during repeated tests, as sand grains scratch its surface. In our experiments electrostatic forces will occur at the interface Alkor foil / sand, but their magnitudes are difficult to determine and their effect on the structures remains unknown. Variability in model results might also be caused by the presence of tiny air pockets trapped below the Alkor foil during adhesion to the base of the sandbox resulting in a slightly uneven surface and varying basal friction conditions.

(2) During the initial stages of the experiment, shortening of the model will result in compaction of the sand grains close to the mobile wall, and hence compaction gradients will form. Adam et al. (2013) could visualize this diffuse, non-localised 1093 
(3) Laboratory climatic conditions varied and in particular the relative humidity might have an influence on the cohesion of the sands, and thus on model results. Forsyth et al. (2002) investigated the influence of atmospheric humidity on glass spheres with different sizes. For the range of grain size used in our experiments (c. 80-200 $\mu \mathrm{m})$, Forsyth et al. (2002) could show that glass spheres only start to show cohesive or stick-slip behaviour at relative humidities $>65 \%$. As most laboratories reported humidities below $65 \%$, humidity is probably not a major factor influencing model results. However, it has to be kept in mind that Forsyth et al. (2002) only investigated the influence of humidity on perfectly spherical grains with identical grain size. Our quartz and corundum sands have an angular grain shape and a heterogeneous grain size distribution, and an uncertainty remains with regard to the role of humidity on the cohesion of our material.

(4) One of the striking results of the present comparison is the large variability in surface slopes, thrust dips, and particularly numbers of thrusts. Large variations occur even between repetition of experiments in the same laboratory. They also do occur along strike of single models. Details of each thrust is little reproducible after substantial shortening, despite our present efforts to remove experimental imperfections. This variability is a feature of the localisation process in frictional materials that cannot be completely removed by an improvement of experimental protocols. The exact location and dip of a thrust depend on minute changes in the distribution of sand grains that promote or delay the onset of dilatation, which has a long term effect upon further shortening. This can also be understood theoretically by recalling the central argument of the critical taper theory: that the wedge will deform to maintain the stress field everywhere on the verge of Coulomb failure. Any model imperfection ruins this simplicity and triggers the next failure, resulting in a system that is highly sensitive to initial conditions and to external perturbations (Mary et al., 2013a).

\subsection{Recommendations and potential improvements}

We recommend that a minimum standard be adhered for experimental descriptions. Often analogue model materials are inadequately characterized and model building and experimental procedures are incomplete. Experimental descriptions should include the 
physical characteristics (e.g. grain size, grain size distribution, grain shape) of the analogue materials, the mechanical properties (e.g. cohesion and angles of internal friction at peak and stable strength, basal friction) and how measured, model construction technique (e.g., physical handling technique, size of sieve mesh, sifting rate, scraping details) and laboratory climatic conditions (temperature, humidity).

In order to reduce the influence of the human factor and minimize initial heterogeneities in material properties introduced during model construction, one could consider using a special sedimentation device for sifting sands. Maillot (2013) built a sedimentation device in an attempt to produce uniform sand packs. For Fontainebleau sand with a $250 \mu \mathrm{m}$ median grain size, Maillot (2013) could show that the density of the resulting sandpack is close to its maximum value, reproducible and uniform. Although the sedimentation device surely presents an advantage in terms of model homogeneity, it requires extensive testing to produce relatively level sand packs. Spatial variations in the thickness of the sand layers cannot be avoided due to downward air currents during infill resulting in a central depression and excess thickness near the four walls. Whereas thickness variations in the centre of the sandbox are mostly below $4 \%$ for a model thickness of c. 3 to $4 \mathrm{~cm}$, variations near the lateral walls are more important (Maillot, 2013). Although a best value of $+6 \%$ is reached, the excess thickness near the walls can be larger than $100 \%$ depending on the type of sand, the sedimentation flux and the number of sieves used (Maillot, 2013). In any case, the sieving process is a central ingredient in model construction. Other devices could be developed for special setups or for producing layered models consisting of different granular materials.

1149 Cubas et al. (2010) performed analogue model experiments using such a sedimentation device to quantify the intrinsic variability of model results. The experiments consisted of shortening an initially subcritical sand wedge resting on a flat sand layer by translating the wall on the wedge side over a distance of $30 \mathrm{~mm}$. By repeating experiments and applying statistical methods to observables measured in final-state cross sections through the central part of the

1154 box (where side-wall effects did not play a role), they could for example show that the error 1155 bar for fault dips are c. $3.3^{\circ}$ for the first pop-up that forms, with forward thrusts dipping at $38^{\circ}$

$1156 \pm 3.2^{\circ}$ and backthrusts at $41 \pm 3.3^{\circ}$. These values are of course dependent on the granular 1157 material used, the experimental protocol and the set-up. Although our experiments 2 and 3 1158 consisted of a different set-up (our models are initially horizontal), used different granular 1159 materials and did not involve the sedimentation device of Maillot (2013), a comparison of the 
error bars for fault dips of forward and backthrusts measured at the top in XRCT sections through the centre of the model shows largely comparable error bars, with forward thrusts dipping at $29 \pm 3^{\circ}$ in both experiments 2 and 3. Backthrusts in experiment 2 have a larger

1163 error bar with faults dipping at $36 \pm 9^{\circ}$, whereas backthrusts in experiment 3 show a smaller

1164 error bar with faults dipping at $30 \pm 2^{\circ}$.

Compaction of the granular model material prior to deformation might also reduce variability in model results. Compaction, however, would need to be done in a systematic and reproducible way, e.g. by shaking or tapping. In addition, one would need to determine the mechanical properties of compacted granular material using an apparatus in which compaction is achieved in an identical way as for the analogue model.

In our model comparison we choose to use quartz and corundum sand used at the laboratory in Bern. These sands have their own specific physical characteristics and mechanical properties. It can not be excluded that the use of another type of sand, with different grain shape, grain size, and grain size distribution, might improve experimental reproducibility. This would require further testing.

Finally, repeating experiments should be performed in order to ensure that intrinsic variability

1179 (in identical setups) is properly defined and smaller than the expected effects related to 1180 (extrinsic) “controlling” factors.

\section{Concluding remarks}

We have made a quantitative comparison of brittle thrust experiments to evaluate the variability among analogue models and to appraise reproducibility and limits of model interpretation. The reasons for variability in analogue model experiments boils down to the system-wide effectiveness of small disturbances. Bearing this in mind the philosophy behind our benchmark was to minimize this by choosing the most simple and most insensitive setups, boundary conditions and materials keeping them as homogeneous as possible in the different

1191 laboratories. For three different thrust wedge experiments, we quantified parameters such as 1192 fault dip, fault spacing, thrust number, thrust formation and surface slope. In contrast to the 1193 model comparison of Schreurs et al. (2006) we made quantitative comparisons of model 
1194 results in sections at least $5 \mathrm{~cm}$ away from the sidewalls, to avoid non-representative results 1195 due to complex interactions between sidewall friction and basal friction.

1197 Our model comparison suggests that one of the sources of experimental variability is related 1198 to slight variations in how material is deposited in the sandbox and how scraping of material 1199 occurred to flatten the surface. Small changes in sifting height, sifting rate, and scraping will result in slightly heterogeneous material densities, which will affect the mechanical properties of the granular material, and result in lateral and vertical differences in peak and basal friction angles, as well as cohesion values once the model is constructed. Initial variations in basal friction are most likely responsible for most of the variability in model results. Part of the variability might also be explained by our choice not to compact models prior to deformation. In our benchmark, shortening causes compaction of the granular materials leading to compaction gradients that are superposed on previous heterogeneities introduced during model construction. Differences in relative humidity between participating laboratories might also have an effect on granular material cohesion and hence on model variability. The influence of humidity on the cohesion of the sands used in our model comparison remains poorly known. Taking into account the experimental studies of Forsyth et al. (2002), however, we consider that its influence on model variability is most likely minimal.

Our observations highlight the limits of up-scaling quantitative analogue model results to nature or for making comparisons with numerical models (Buiter et al., 2016). It will remain difficult to scale quantitative results such as number of thrusts, spacing between forward thrusts, or width of pop-up structures from model to nature. The way forward is perhaps to build statistical descriptions of the measured parameters rather than using single values. These would in turn provide more reliable data for a comparison to numerical simulations.

Our model comparison shows that even for simple plane-strain experiments with prescribed stringent model construction techniques, the human factor plays a decisive role, and even when one modeler repeats the experiment, the quantitative model results show considerable variability. Although this might at first seem a discouraging conclusion, the failure of the models to achieve perfect replicability despite our precautions can be considered a success in documenting the importance of initial model heterogeneity. As is the case for natural thrust

1226 wedges, the initial undeformed sand model is not perfectly homogeneous throughout, but already has slight variations in mechanical properties such as internal friction, basal friction, 
internal cohesion and basal cohesion. Small differences in these parameters will affect how, where and when the first thrusts form and will affect the details of the timing and location of subsequent thrusts.

The variability reported in our benchmark is considerable and should serve the analogue modeling community as a constraint on the best expected "precision" of models. We can assume that as model setups become more complex (e.g. by introducing detachment layers, erosion, sedimentation, lateral and vertical changes in material geometry, etc.) the "precision" will drop drastically. We hope that this benchmark serves to sensitize the community and helps to prevent over-interpretation of analogue models especially in view of recent developments that allow quantitative measurements to be made easily at high precision using laser scanning or image correlation techniques.

\section{Acknowledgments}

This study was supported by SNF Grant 200020-109320, 200020-122143 and 200021-140608 (Guido Schreurs), Discovery and Equipment grants from the Natural Sciences and Engineering Research Council of Canada, NSERC (Alexander Cruden), the Fundação de Amparo à Pesquisa do Estado de Minas Gerais (Fapemig), CRA 871/06 (Caroline J.S. Gomes), and the Swedish Research Council, Grant 2008-3443 (Faramarz Nilfouroushan) .

\section{References}

Adam, J., Urai, J.L., Wieneke, B., Oncken, O., Pfeiffer, K., Kukowski, N., Lohrmann, J., Hoth, S., van der Zee, W., Schmatz, J., 2005. Shear localisation and strain distribution during tectonic faulting - new insights from granular-flow experiments and highresolution optical image correlation techniques. Journal of Structural Geology 27, 283301.

Adam, J., Klinkmüller, M., Schreurs, G., Wieneke, B., 2013. Quantitative 3D strain analysis in analogue experiments simulating tectonic deformation: Integration of X-ray computed tomography and digital volume correlation techniques. Journal of Structural Geology, 55, 127-149. 
1262

1263

1264

1265

1266

1267

1268

1269

1270

1271

1272

1273

1274

1275

1276

1277

1278

1279

1280

1281

1282

1283

1284

1285

1286

1287

1288

1289

1290

1291

1292

1293

1294

Bernard, S., Avouac, J.-P., Dominguez, S., Simoes, M., 2007. Kinematics of fault-related folding derived from a sandbox experiment. Journal of Geophysical Research 112, J B03S12, doi:10.1029/2005JB004149.

Buiter, S.J.H., 2012. A review of brittle compressional wedge models. Tectonophysics 530531, 1-17, doi: 10.1016/j.tecto.2011.12.018..

Buiter, S.J.H., Schreurs, G., Albertz, M., Gerya, T.V., Kaus, B., Landry, W., Le Pourhiet, L., Mishin, Y., Egholm, D.L., Cooke, M., Maillot, B., Thieulot, C., Crook, T., May, D., Souloumiac, P., and Beaumont, C., 2016. Benchmarking numerical models of brittle thrust wedges. Journal of Structural Geology, http://dx.doi.org/10.1016/j.jsg.2016.03.003

Colletta, B., Bale, P., Ballard, J.F., Letouzey, J., Pinedo, R., 1991. Computerized Y-ray tomography analysis of sandbox models: examples of thin-skinned thrust systems. Geology 19, 1063-1067.

Costa, E., Vendeville, B., 2004. Experimental insights on the geometry and kinematics of fold-and-thrust belts above weak, viscous evaporitic décollement: reply to comments by Hemin Koyi and James Cotton. Journal of Structural Geology 26, 2139-2143.

Cubas, N., Maillot, B., Barnes, C., 2010. Statistical analysis of an experimental compressional sand wedge. Journal of Structural Geology 32, 818-831.

Dahlen, F.A., Suppe, J., 1988. Mechanics, growth, and erosion of mountain belts. Geological Society of America, Special Paper 218, 161-178.

Dahlen, F.A., Suppe J., Davis, D., 1984. Mechanics of fold-and-thrust belts and accretionary wedges: cohesive Coulomb theory. Journal of Geophysical Research 89, 10087-10101.

Forsyth, A.J., Hutton, S., Rhodes, M.J., 2002. Effect of cohesive interparticle force on the flow characteristics of granular materials. Powder Technology 126, 150-154.

Gomes, C.J.S., 2013. Investigating new materials in the context of analog-physical models. Journal of Structural Geology 46, 158-166.

Huiqi, L., McClay, K.R., Powell, D., 1992. Physical models of thrust wedges. In: McClay, K.R. (Ed.), Thrust Tectonics, Chapmann \& Hall, London, 71-81.

Krantz, RW., 1991. Measurements of friction coefficients and cohesion for faulting and fault reactivation in laboratory models using sand and sand mixtures. Tectonophysics 202, 319-333.

Lohrmann, J., Kukowski, N., Adam, J., Oncken, O., 2003. The impact of analogue material properties on the geometry, kinematics, and dynamics of convergent sand wedges. Journal of Structural Geology 25, 1691-1711. 
Maillot, B., 2013. A sedimentation device to produce uniform sand packs. Tectonophysics 593, 85-94.

Mary B.C., Maillot, B., Leroy, Y.M. 2013a. Deterministic chaos in frictional wedges revealed by convergence analysis, International Journal for Numerical and Analytical Methods in Geomechanics, doi: 10.100/nag.2177.

Mary B.C., Maillot, B., Leroy, Y.M., 2013b. Predicting orogenic wedge styles as a function of analogue erosion law and material softening, Geochemistry, Geophysics, Geosystems 14, doi:10.1002/ggge.20262.

Panien, M., Schreurs, G., Pfiffner, O.A., 2006. Mechanical behaviour of granular materials used in analogue modeling: insights from grain characterisation, ring-shear tests and sandbox tests. Journal of Structural Geology 28, 1710-1724, doi: 10.1016/j.tecto.2011.06.022.

Rosenau, M., Lohrmann, J., Oncken, O., 2009. Shocks in a box: An analogue model of subduction earthquake cycles with application to seismotectonic forearc evolution. Journal of Geophysical Research 114, B1, DOI: 10.1029/2008JB005665.

Schellart, W.P., 2000. Shear test results for cohesion and friction coefficients for different granular materials: scaling implications for their usage in analogue modeling. Tectonophysics 324, 1-16.

Schreurs, G., Buiter, S.J.H., Boutelier, D., Corti, G., Costa, E., Cruden, A., Daniel, J.-M., Hoth, S., Koyi, H., Kukowski, N., Lohrmann, J., Ravaglia, A., Schlische, R.W., Withjack, M.O., Yamada, Y., Cavozzi, C., DelVentisetti, C., Elder Brady, J.A., Hoffmann-Rother, A., Mengus, J.-M., Montanari, D., Nilforoushan, F., 2006. Analogue benchmarks of shortening and extension experiments. In: Buiter, S.J.H. and Schreurs, G. (Eds), Analogue and Numerical Modeling of Crustal-Scale Processes. Geological Society, London, Special Publications 253, 1-25.

Schulze, D., 2008. Pulver und Schüttgüter - Fliesseigenschaften und Handhabung, Springer, Berlin.

Stockmal, G.S., CBeaumont, C., Nguyen, M., Lee, B., 2007. Mechanics of thin-skinned foldand-thrust belts: Insights from numerical models. Geological Society of America Special Paper 433, 63-98.

Souloumiac P., Krabbenhoft, K., Leroy, Y.M., B. Maillot, B., 2010. Failure in accretionary wedges with the maximum strength theorem: numerical algorithm and $2 \mathrm{D}$ validation, Computational Geosciences, doi:10.1007/s10596-010-9184-4. 
1328 Souloumiac, P., Maillot, B., Leroy, Y. M., 2012. Bias due to side wall friction in sand box 1329 experiments. Journal of Structural Geology 35, 90-101.

1330 Zhao, W.-L., Davis, D.M., Dahlen, F.A., Suppe, J., 1986. Origin of convex accretionary 1331 wedges: evidence from Barbados. Journal of Geophysical Research 91, 10246-10258. 
1339 Fig. 1. Experimental set-up used in model comparison experiments by Schreurs et al., (2006). Model 1340 consists of a $3.5 \mathrm{~cm}$-thick sand layer with an embedded microbeads layer and an overlying sand wedge 1341 with a surface slope of $10^{\circ}$ adjacent to the mobile wall. All walls are covered by Alkor foil. Figure reproduced from Schreurs et al. (2006) with permission from the Geological Society of London.

Fig. 2. Model comparison showing cross sections through thrust wedge after 2, 6 and $14 \mathrm{~cm}$ of shortening. The experimental set-up is shown in Fig. 1. The sections of Bern and IFP Rueil Malmaison are X-ray computer tomography (XRCT) images through the center of the model, whereas the remaining sections are sidewall observations. Microbeads layer indicated by " $m$ ". Figure modified after and reproduced from Schreurs et al. (2006) with permission from the Geological Society of London.

Fig. 3. Physical characteristics of the quartz and corundum sand used in the experiments (modified after Panien et al., 2006). Upper and lowermost images are photographs and SEM images, respectively. Width of each SEM image is $1740 \mu \mathrm{m}$.

Fig. 4. Shear stress plotted versus shear strain for quartz sand (modified from Lohrmann et al., 2003; Panien et al., 2006). Strain softening from peak strength to stable strength correlates with dilation of sand.

Fig. 5. Zoom of critical taper curves for cohesionless sand at peak strength $\left(\phi_{\mathrm{p}}=36^{\circ}, \phi_{\mathrm{b}}=15^{\circ}\right.$ and $\mathrm{C}=$ $0 \mathrm{~Pa})$, cohesionless sand at stable strength $\left(\phi_{\mathrm{s}}=31^{\circ}, \phi_{\mathrm{b}}=15^{\circ}\right.$ and $\left.\mathrm{C}=0 \mathrm{~Pa}\right)$, and a cohesive sand at peak strength with depth-dependent cohesion $\left(\phi_{\mathrm{p}}=36^{\circ}, \phi_{\mathrm{b}}=15^{\circ}\right.$ and $\mathrm{C}=20 \mathrm{~Pa} \mathrm{~cm}^{-1}$ times $\mathrm{z}$, with $\mathrm{z}=$ depth, following Zhao et al. (1986)).

1364 Fig. 6. Schematic illustration of measurements of a) surface slope, b) forward thrust spacing, and c) thrust dip angles. Surface slope is measured as the best fitting line through the valleys (Stockmal et al., 2007) and can only be determined once at least 2 thrusts have formed. Thrust spacing is measured horizontally from a newly initiated in-sequence forward thrust to the previously formed forward thrust. 
Fig. 7. Top view photograph illustrating position of cross sections at $25 \%$ (1), $50 \%-2 \mathrm{~cm} \mathrm{(2),} 50 \%$ (3), $50 \%+2 \mathrm{~cm}$ (4), and $75 \%$ (5) of model width (measured parallel to mobile wall, which moves here from bottom to top). Model width is $80 \mathrm{~cm}$ in this particular experiment.

Fig. 8. Model set-up for experiment 1.

Fig. 9. Model building procedure for experiment 1 shown in cross section. A template with the shape of the final wedge is attached on top of each sidewall to guide the scraper (see Appendix A-2). Stippled line indicates sand wedge before final scraping.

Fig. 10. Evolution of experiment 1 model run at Bern after 0,2 and $4 \mathrm{~cm}$ of shortening (a) XRCT sections through centre of model, (b) top view photographs of model.

Fig. 11. Cross sections through centre of experiment 1 models after $4 \mathrm{~cm}$ of shortening. Sections of Bern, GFZ@Bern, and IFP are XRCT images

Fig. 12. Model set-up for experiment 2.

Fig. 13. Cross-sectional evolution through centre of experiment 2 models after 1, 2, 6 and $10 \mathrm{~cm}$ of shortening as observed in XRCT images.

Fig. 14. Quantitative comparison of experiment 2 models analysed by XRCT. (a) Amount of shortening at which a forward thrust forms at centre of model. (b) Spacing to previously formed forward thrust at the moment of initiation of a new, in-sequence forward thrust.

Fig. 15. Dip angles of successive in-sequence forward (a) and back thrusts (b) in centre of experiment 2 XRCT models, measured at top, middle and bottom.

Fig. 16. Surface slope evolution at centre of experiment 2 XRCT models. Only values that could be reliably measured in XRCT images are given.

Fig. 17. Cross sections through centre of experiment 2 models after $10 \mathrm{~cm}$ of shortening. Width of each panel shown is $25 \mathrm{~cm}$. Note that some labs added a layer of sand before cutting the model. Cross sections from Lille $2 \mathrm{~A}$ and $2 \mathrm{~B}$ are at $50 \%-2 \mathrm{~cm}$ position. Image quality of cross sections from Stanford $2 \mathrm{~A}$ and $2 \mathrm{~B}$ was not good enough for reproduction. 
1406 Fig. 18. Top views of experiment 2 models after $10 \mathrm{~cm}$ of shortening showing along-strike structural

1407 variability. Movement of mobile wall is from bottom to top Note that Lille 2A and 2B models have a

1408 grid of corundum sand imprinted on the surface, whereas Mexico 2A and 2B models used prescribed

1409 sand mixed with dark sand particles. All photos are shown at the same scale, given in the top left

1410 photo.

1412 Fig. 19. Cross sections after $10 \mathrm{~cm}$ shortening for experiment 2 models at positions $25 \%, 50 \%-2 \mathrm{~cm}$, $141350 \%, 50 \%+2 \mathrm{~cm}$ and $75 \%$ (see Fig. 6) showing along-strike structural variability. Note that some 1414 laboratories added a post-kinematic sand layer before wetting and sectioning.

1416 Fig. 20. Surface slope after $10 \mathrm{~cm}$ of shortening at $25 \%, 50 \%$ and $75 \%$ positions for experiment 2 1417 models.The surface slope could not be reliably measured on all cross-sectional images. Surface slopes

1418 for Lille 2A and Lille 2B models were measured at $50 \%-2 \mathrm{~cm}$ position. Numbers above symbols 1419 indicate difference between maximum and minimum slope angle within one particular model and are 1420 only given for those models in which the surface slope could be determined at all three positions. 1421 Surface slope values along one sidewall ( $0 \%$ position) are given for comparison and are generally 1422 higher.

Fig. 21. Number of forward and back thrusts at $25 \%, 50 \%$ and $75 \%$ position after $10 \mathrm{~cm}$ of shortening

1425 for experiment 2 models. Numbers above symbols indicate along-strike differences in number of 1426 thrusts and are only given for those models, in which thrusts could be reliably determined at all three 1427 positions.

Fig. 22. Model setup for experiment 3.

Fig. 23. Cross sections at 1, 2, 6 and $10 \mathrm{~cm}$ for all experiment 3 models analysed by XRCT.

Fig. 24. Dip of successive forward thrusts at time of initiation through centre of model, measured at bottom, middle and top in experiment 3 XRCT models.

1436 Fig. 25. Evolution of surface slope through centre of experiment 3 XRCT models. The lines 1437 connecting measurements illustrate the oscillating behaviour of the surface slope, which tends to 1438 become less with increasing shortening. Numbers above symbols indicate the difference in maximum and minimum surface slope between the five models at a specific shortening increment.

1441 Fig. 26. Cross sections after $10 \mathrm{~cm}$ of shortening through centre of experiment 3 models. Cross section 1442 of Stanford 3A is not shown, because image quality was insufficient for reproduction. 
1444 Fig. 27. Top views after $10 \mathrm{~cm}$ of shortening for experiment 3 models. Lille model has a surface grid 1445 of corundum sand.

1447 Fig. 28. Cross sections after $10 \mathrm{~cm}$ shortening for experiment 3 models at positions $25 \%, 50 \%-2 \mathrm{~cm}$, $144850 \%, 50 \%+2 \mathrm{~cm}$ and $75 \%$ of model width (see Fig. 7).

Fig. 29. Surface slope after $10 \mathrm{~cm}$ of shortening at $25 \%, 50 \%$ and $75 \%$ position for experiment 3 models

Fig. 30. Number of forward thrusts after $10 \mathrm{~cm}$ of shortening at $25 \%, 50 \%$ and $75 \%$ position for experimental 3 models. Note that only those thrusts were considered that produced a noticeable offset at the surface. The number of thrusts in Stanford 3A and 3B models could not be reliably determined

1456 due to poor image quality.

1458 Appendix A: Model construction techniques

1459 Appendix A-1: Mesh sieve

1460 Appendix A-2: Scraper to remove excess sand

Table 1. Range of mechanical properties of quartz and corundum sand obtained with a ring-shear tester. Values are rounded to nearest degree for friction angles and to nearest whole number for cohesion. $n$ is number of ringshear tests at normal stresses ranging from c. 500 to 2240 Pa.

Table 2. Overview of laboratory climatic conditions and model widths. Most laboratories performed experiments

14702 and 3 twice, and range of values for room temperature and relative humidity are indicated. Exceptions to the 1471 prescribed modeling procedure are also given. 


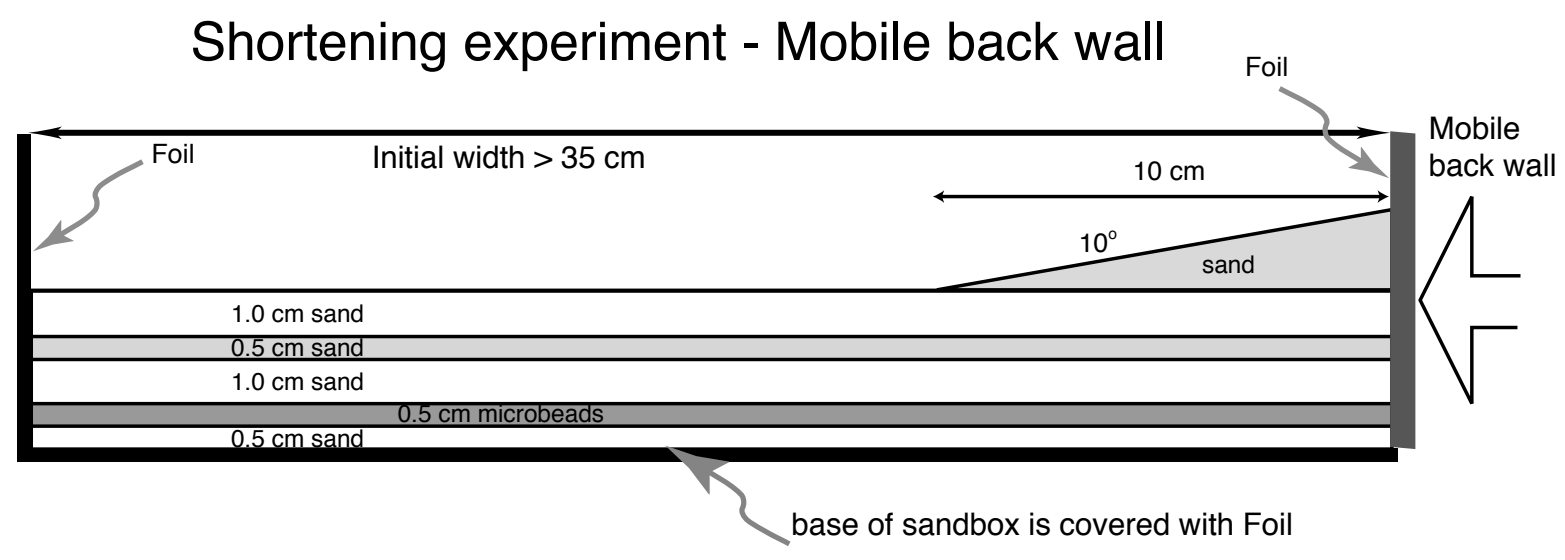

Fig. 1 

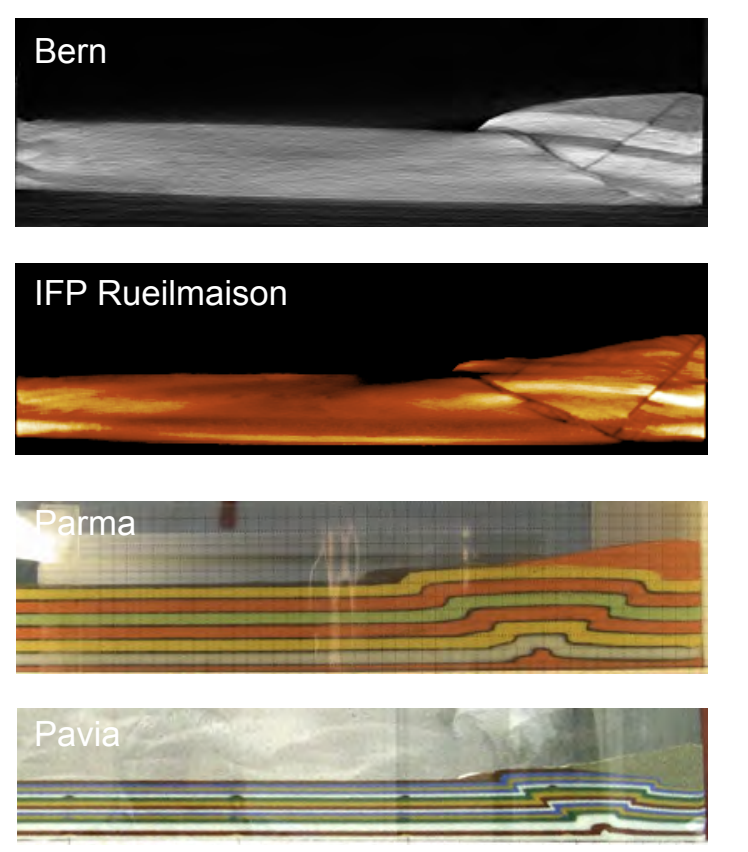

Tóronto

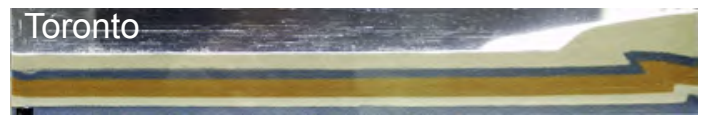

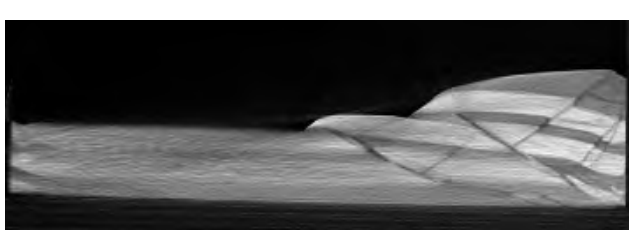
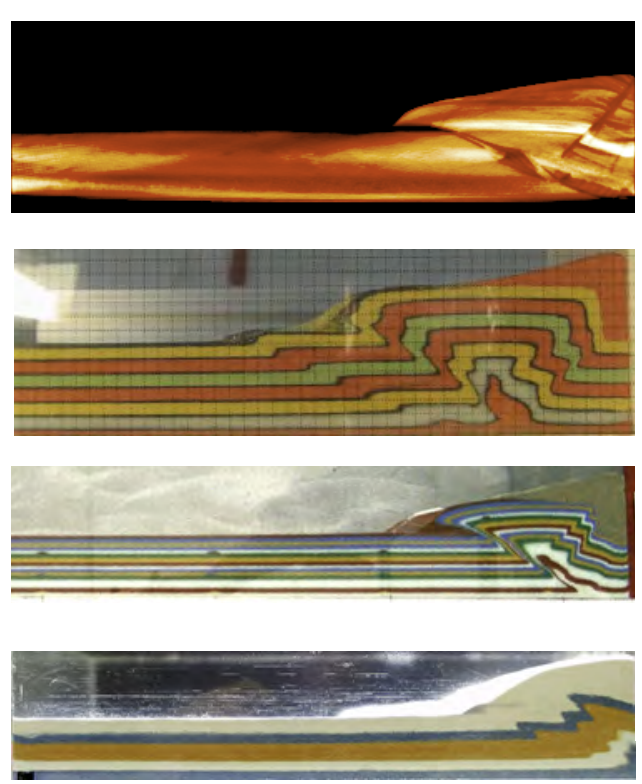
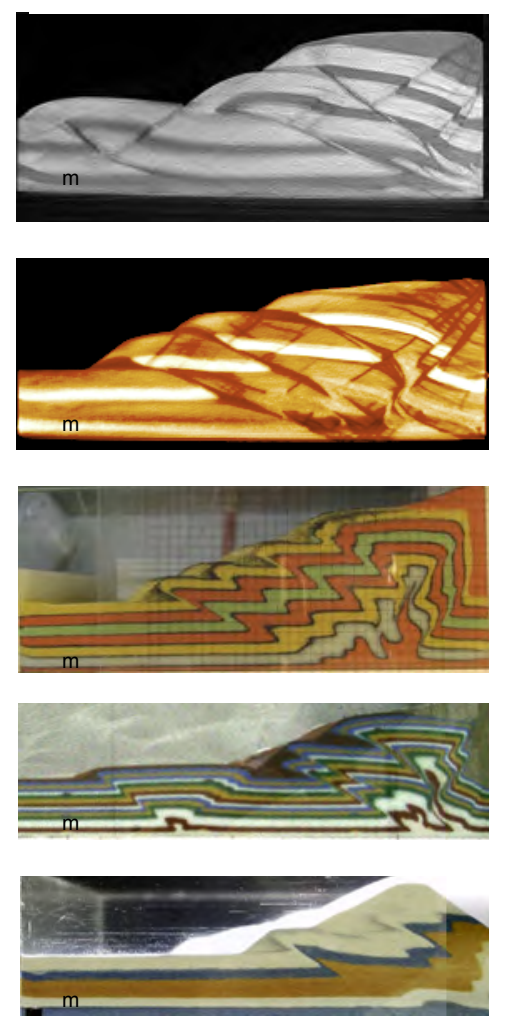


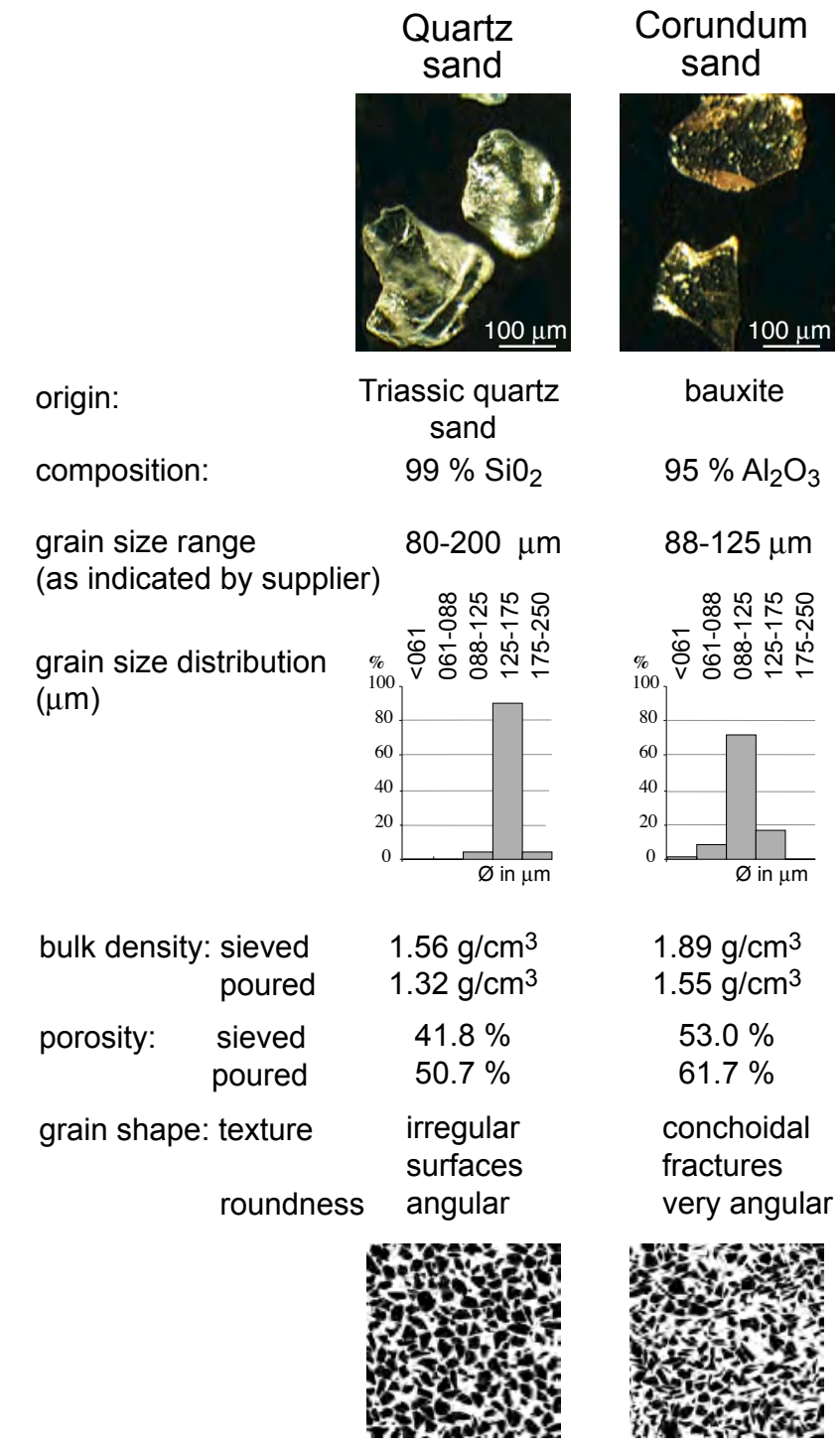

Corundum 


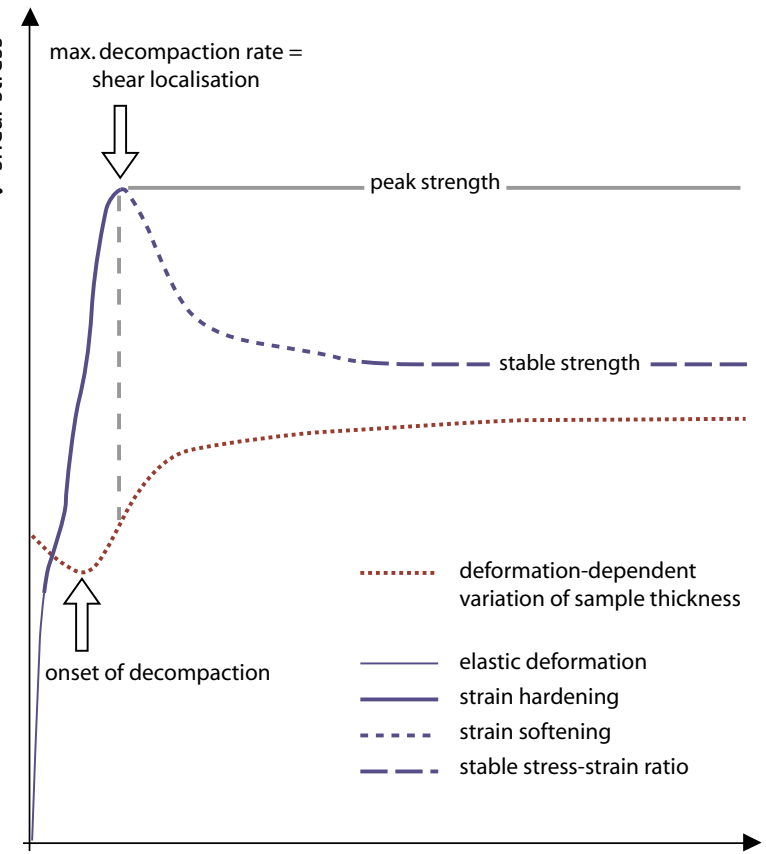

$\gamma$ shear strain 


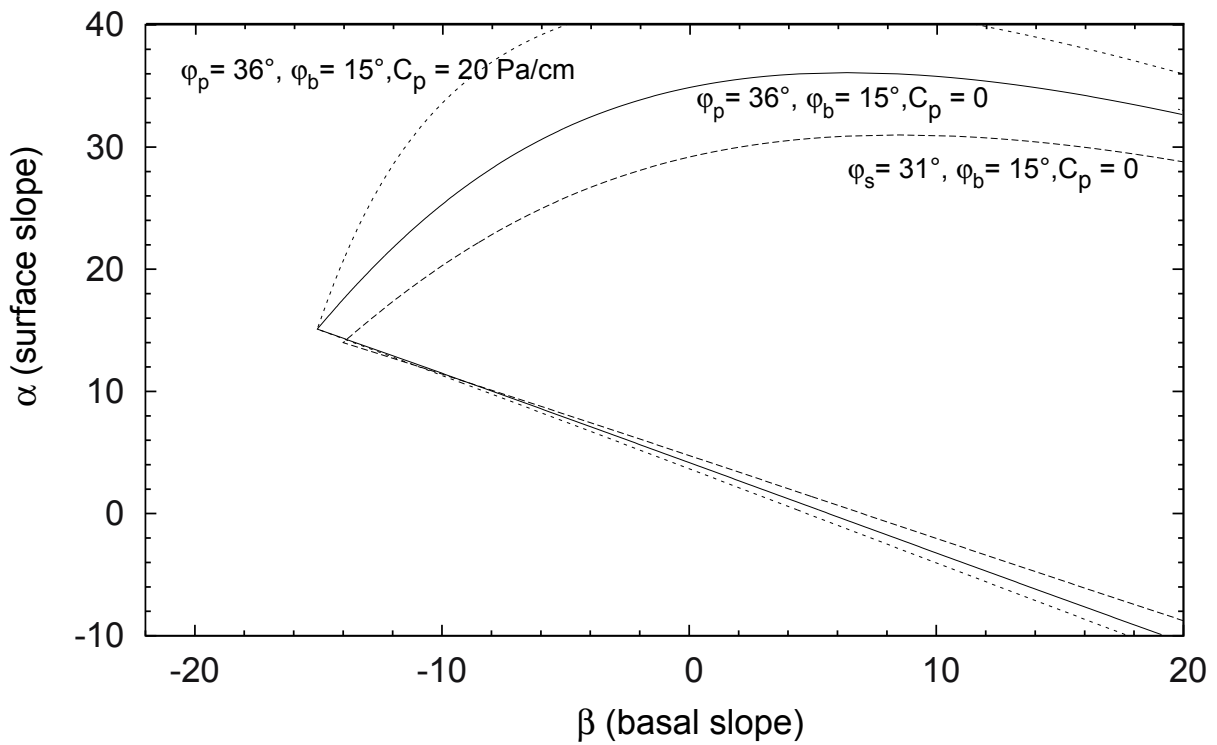



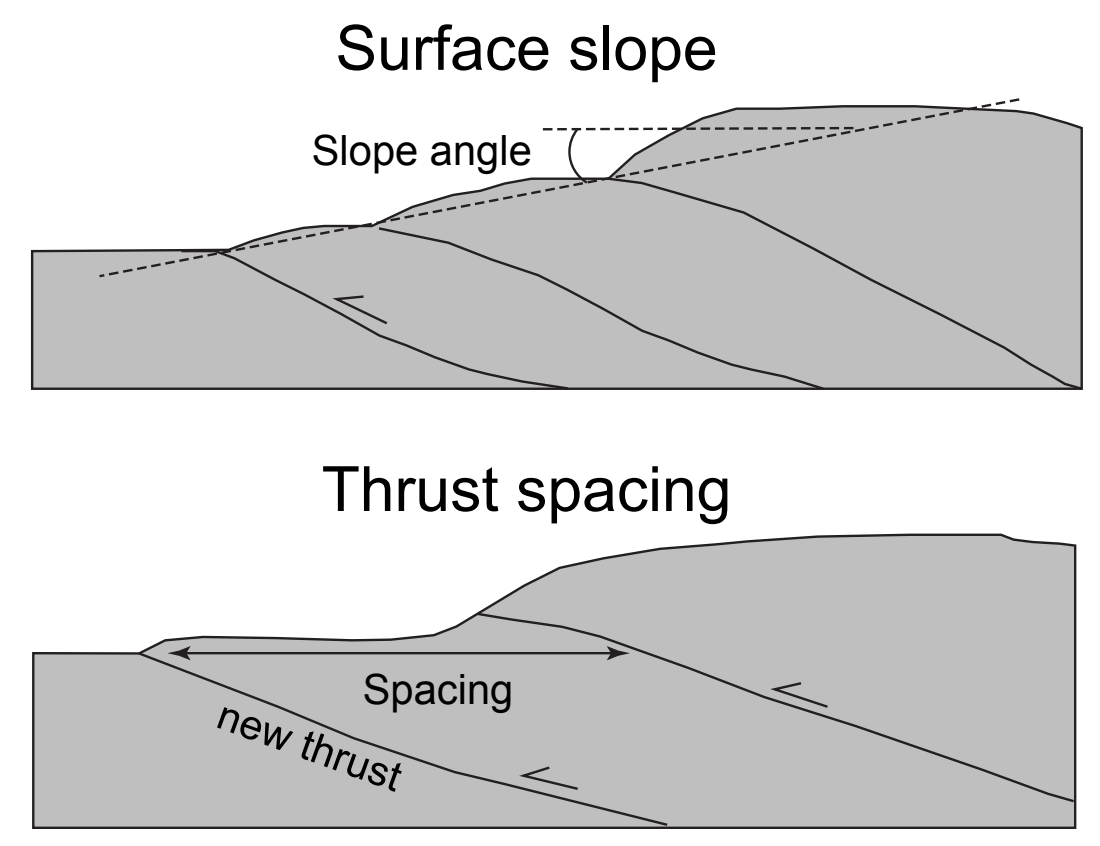

Thrust dip angle

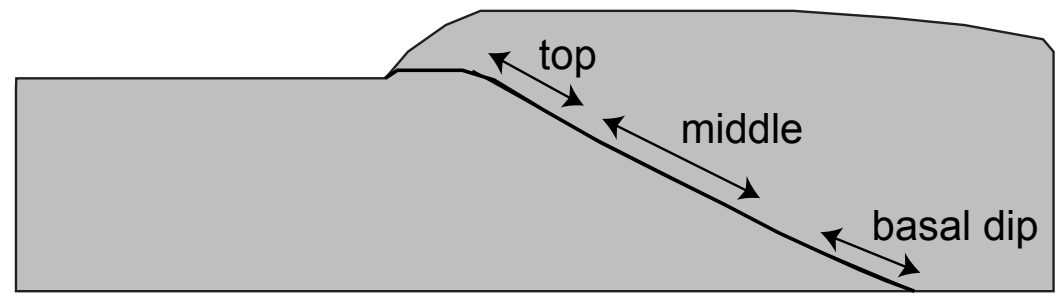




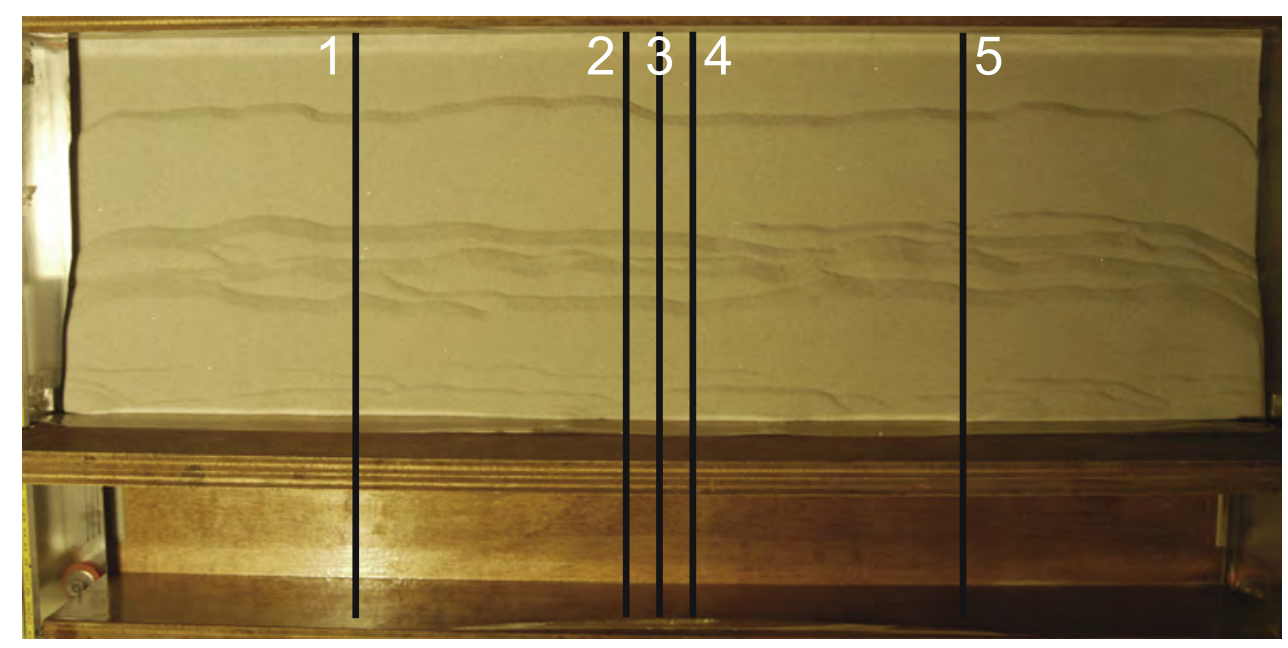




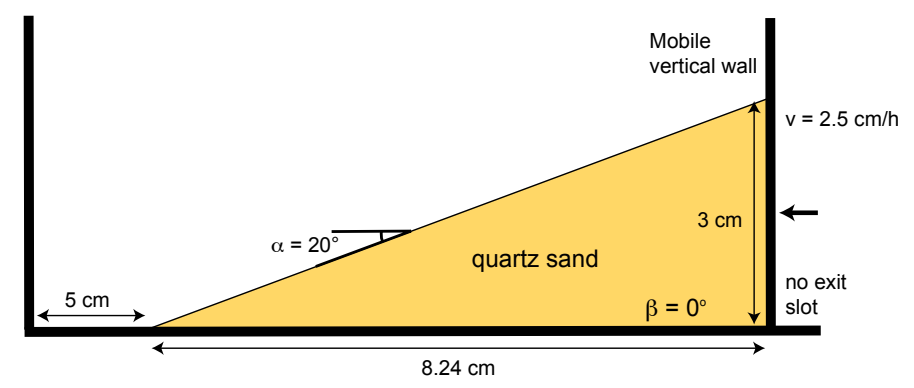




\section{Fixed wall}

Mobile wall

(a)

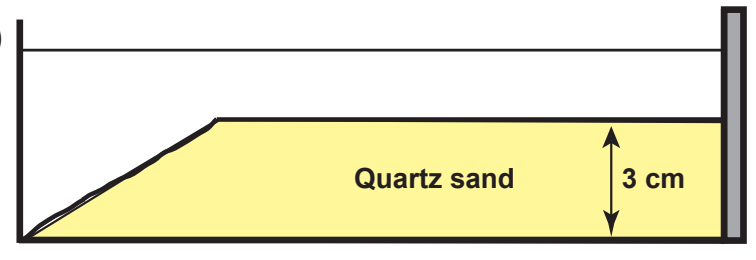

(b)

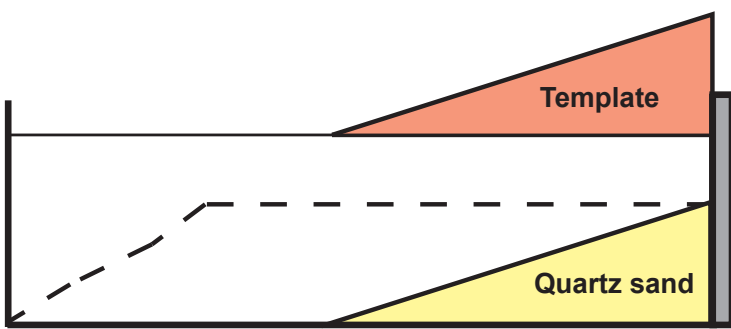



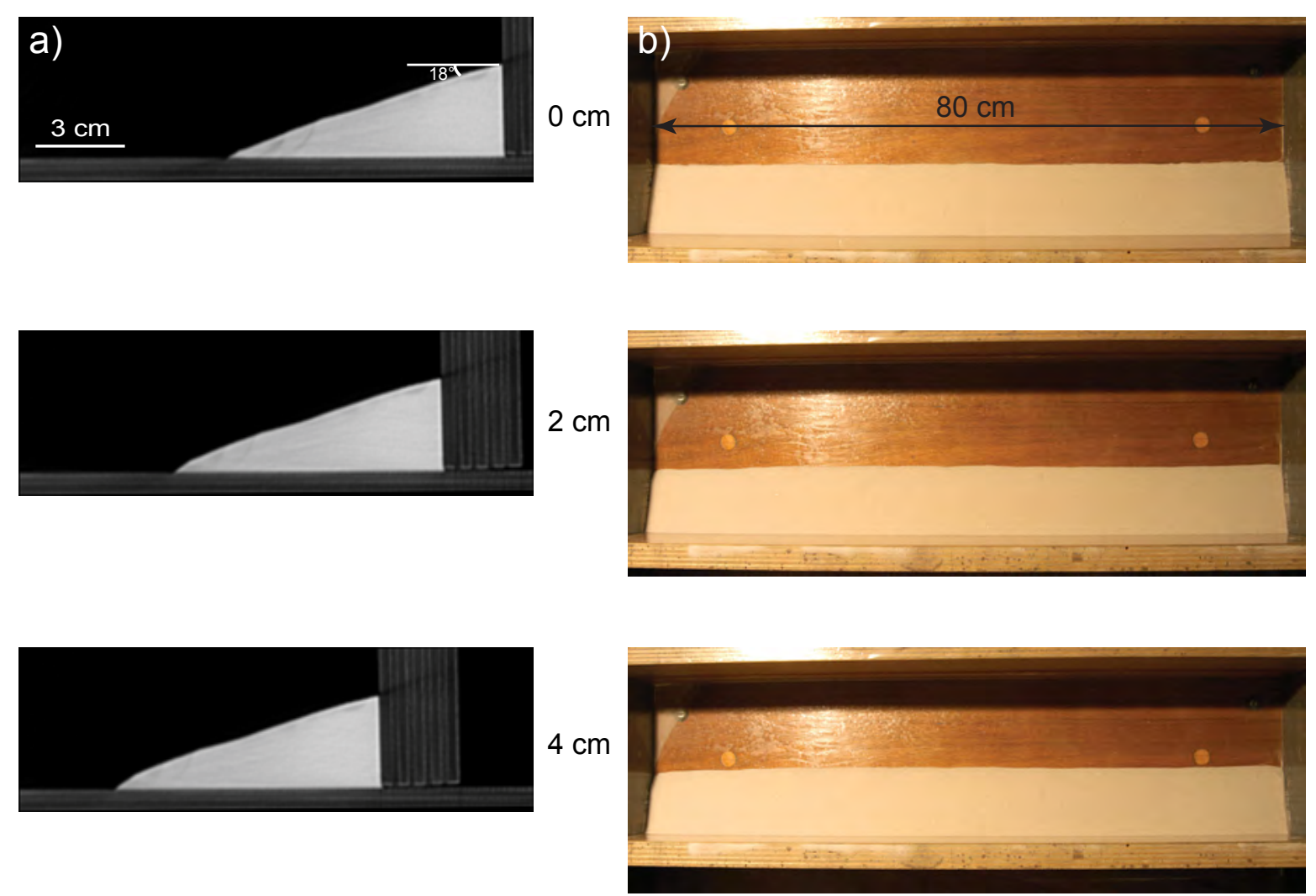


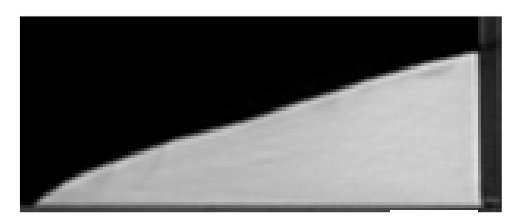

Bern
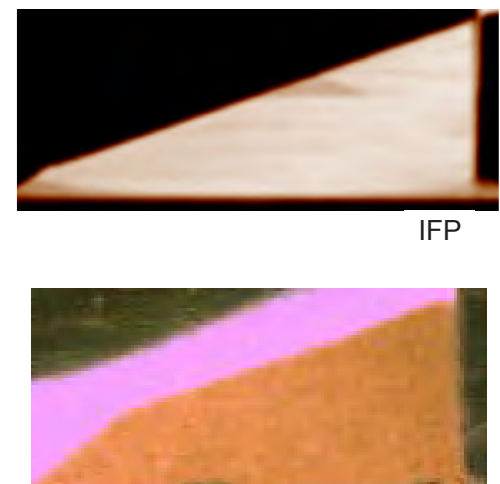

Mexico

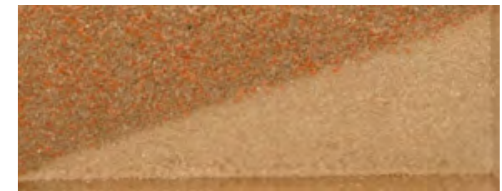

Toronto

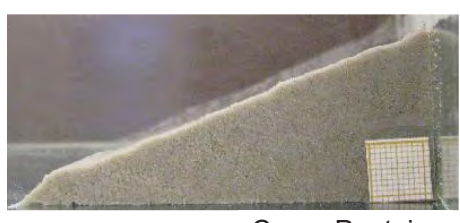

Cergy-Pontoise
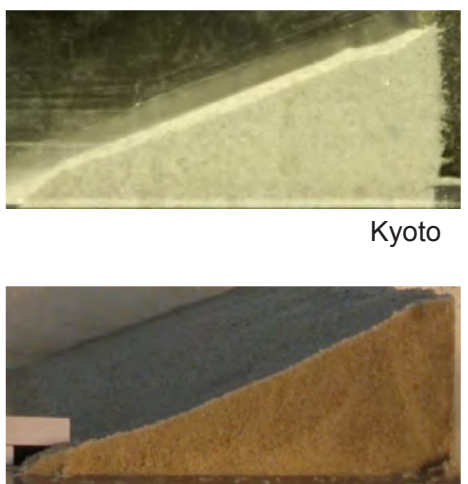

Ouro Preto

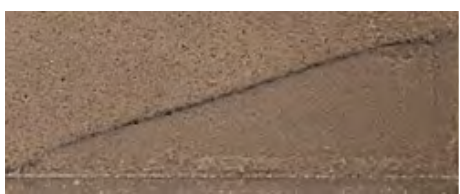

Uppsala

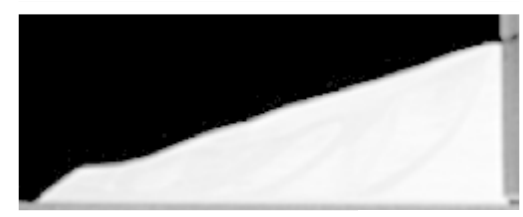

GFZ@Bern
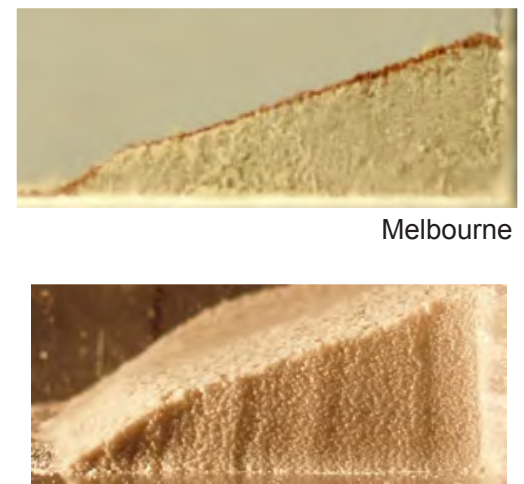

Piscataway 


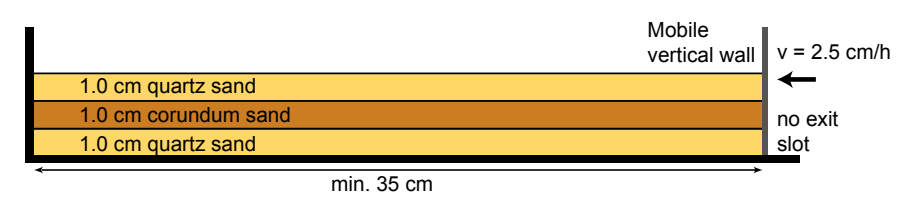




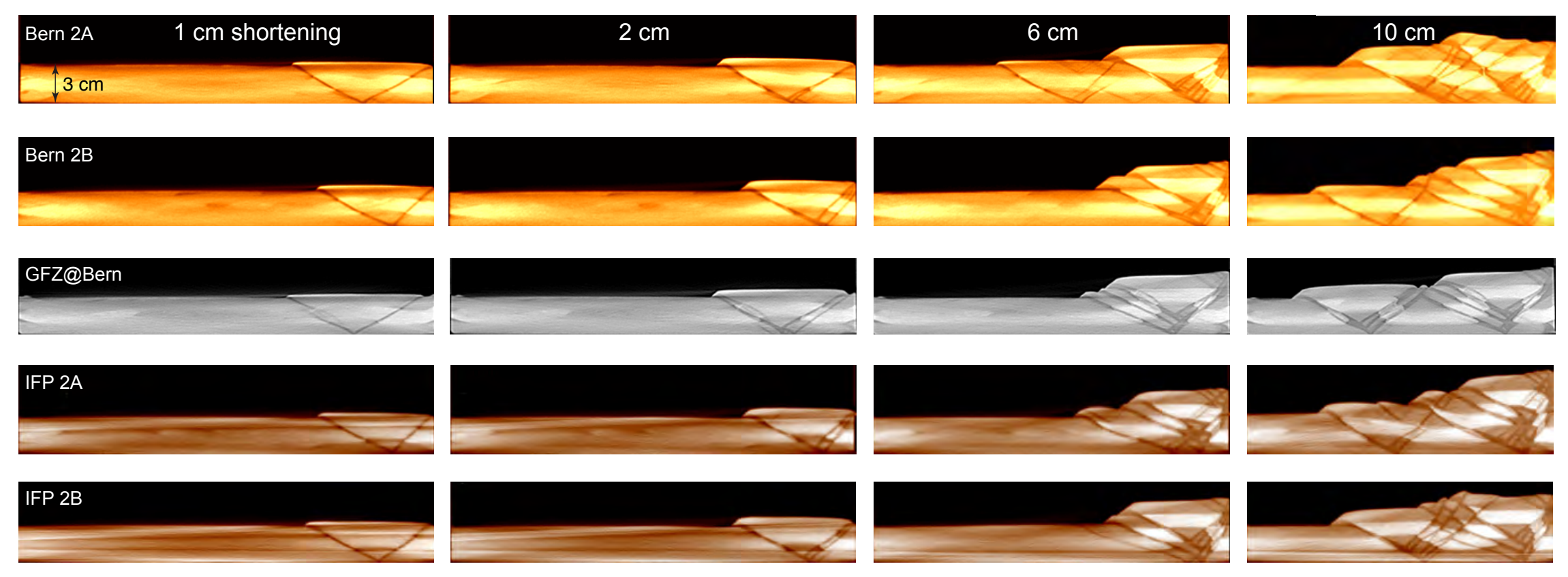



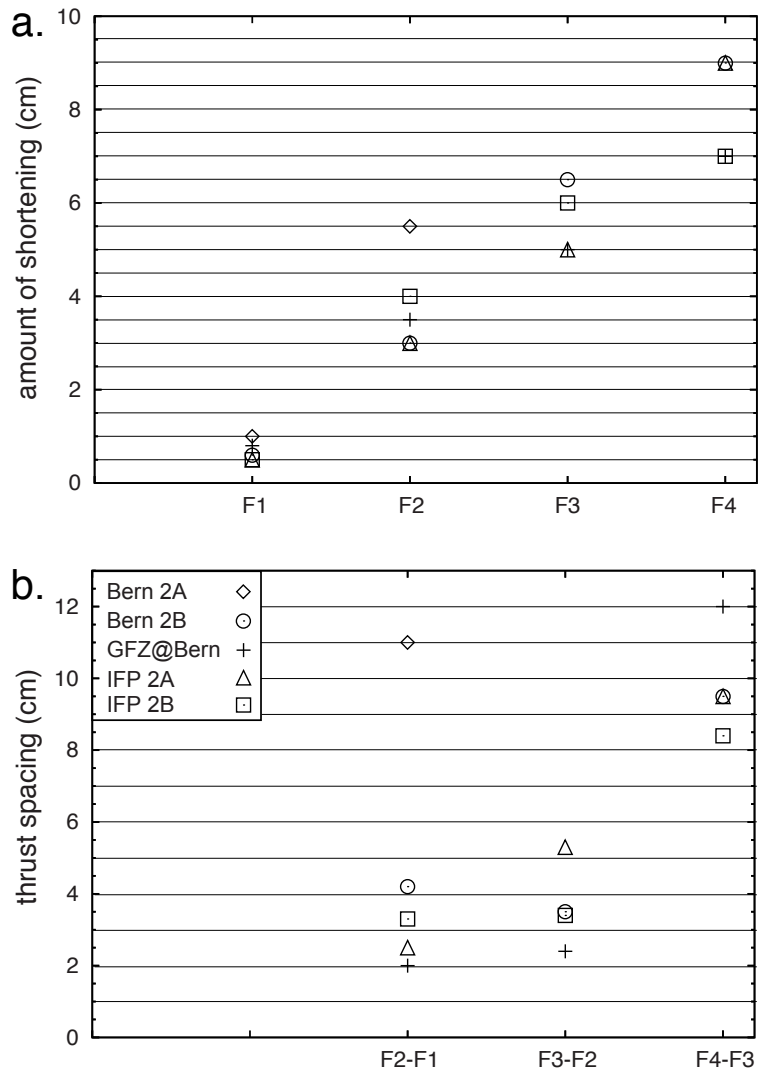

forward thrust number 

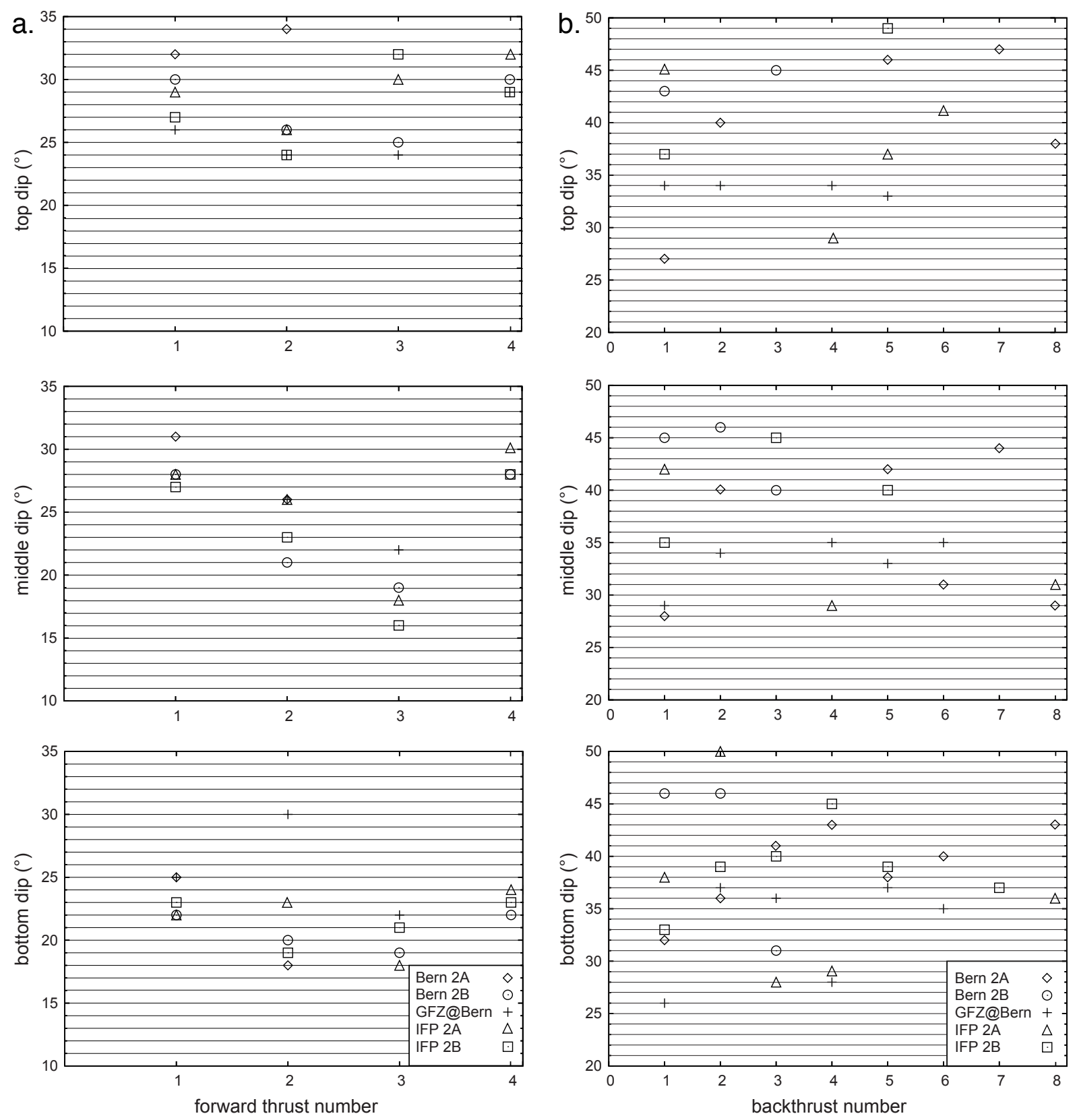


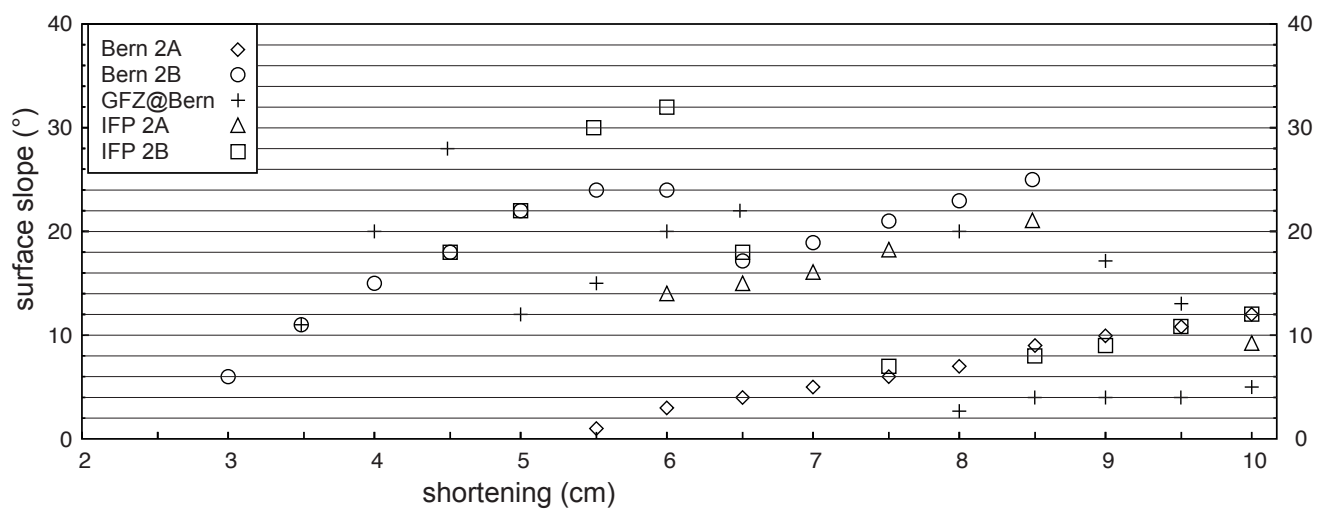



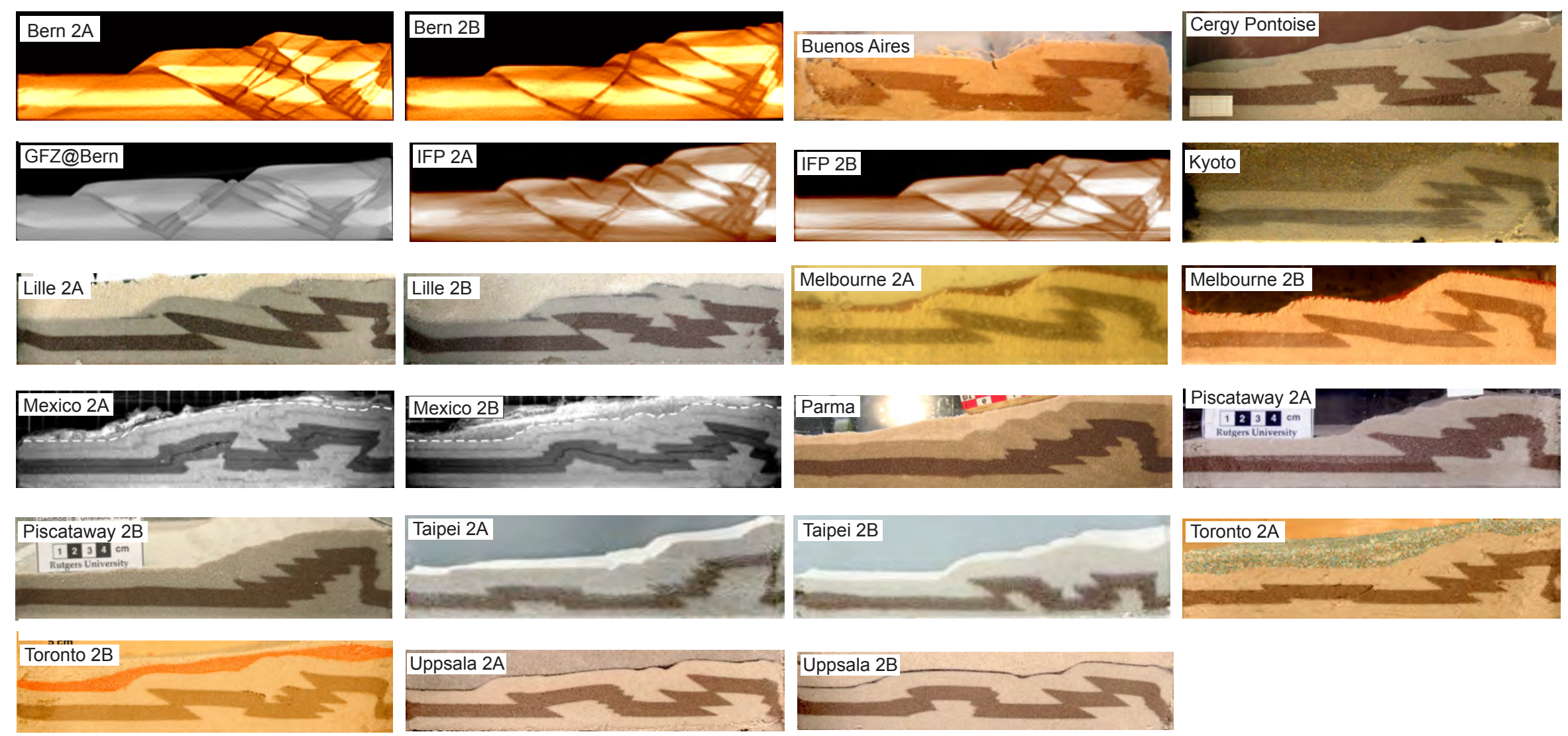

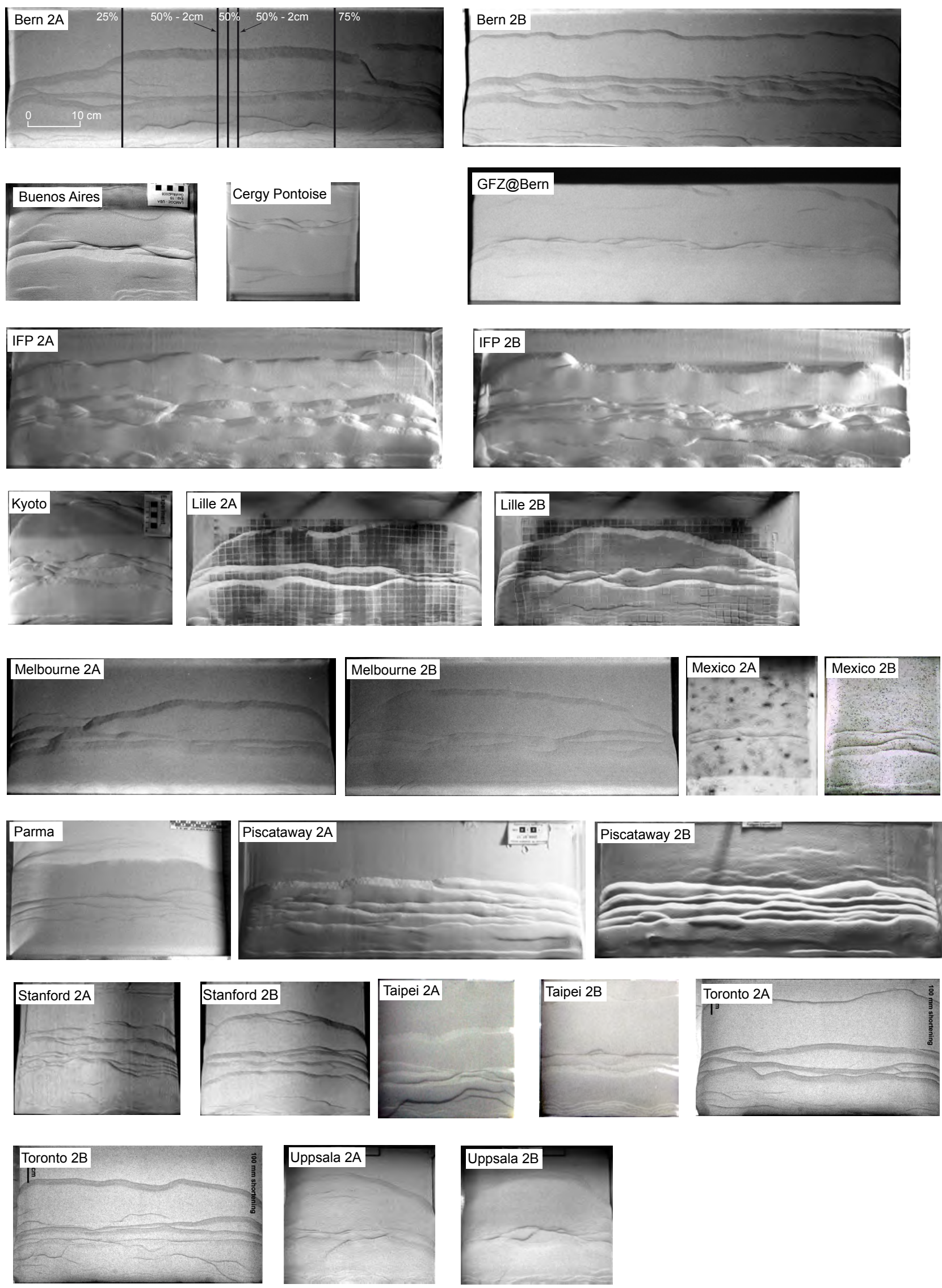


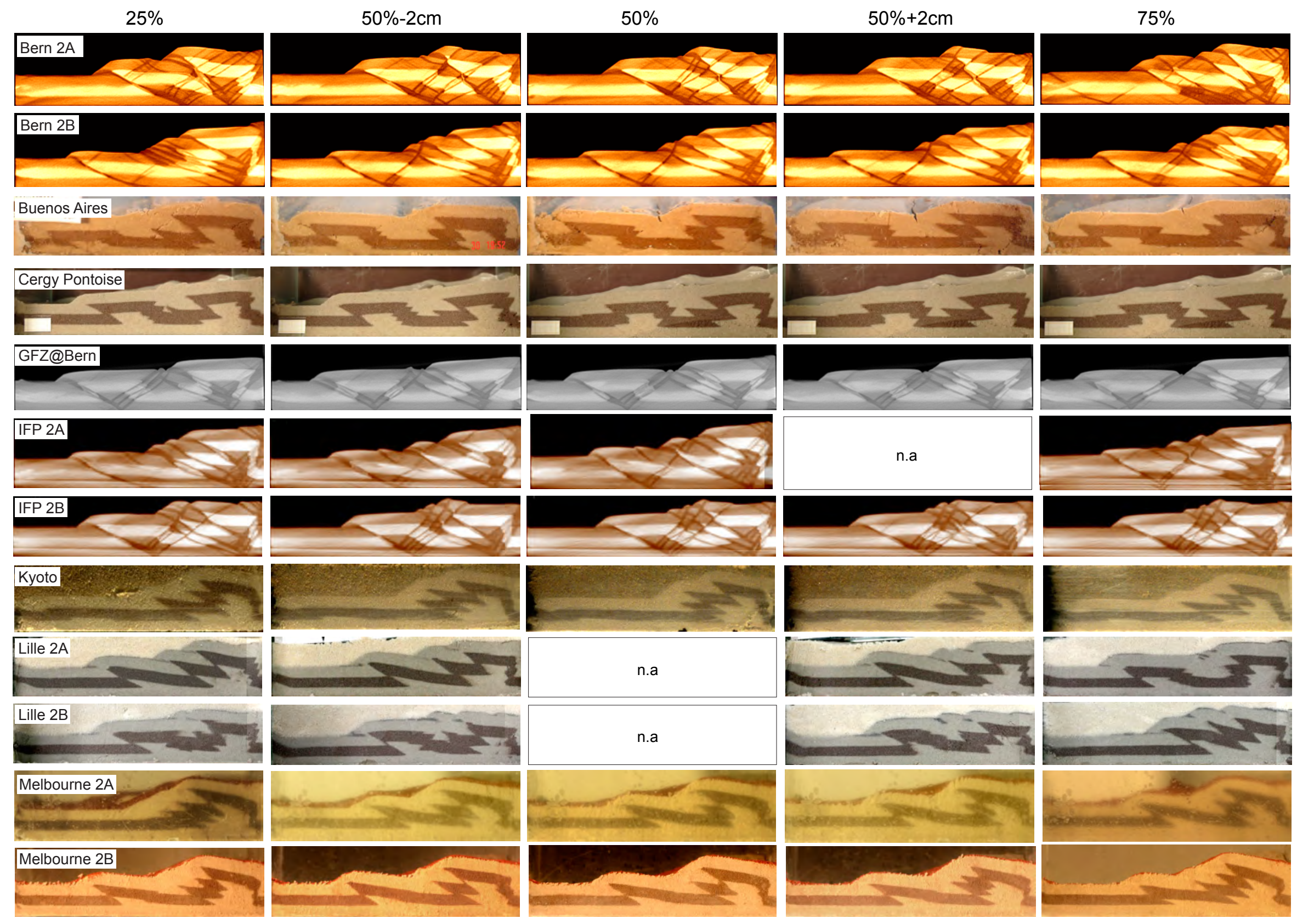



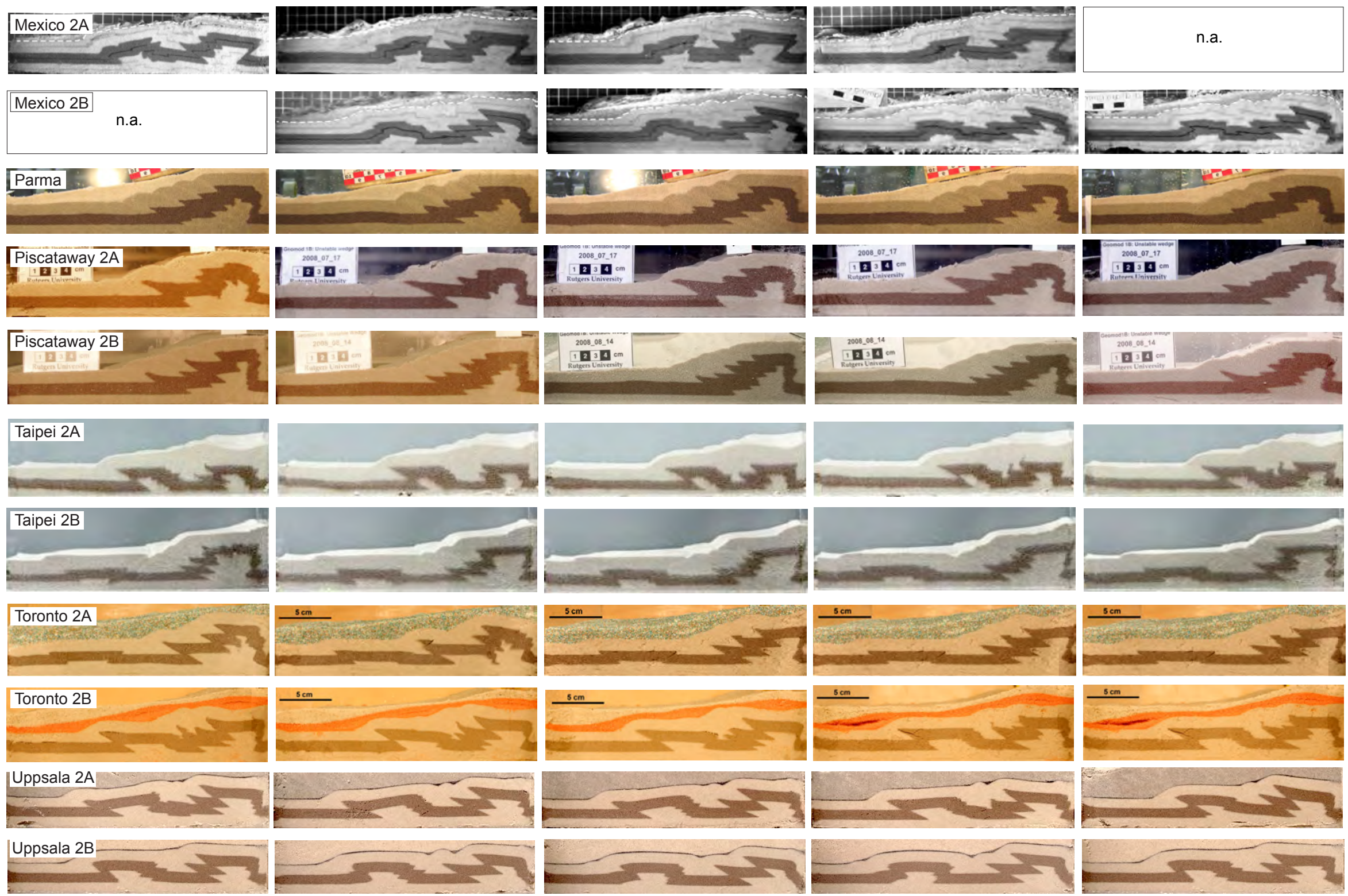


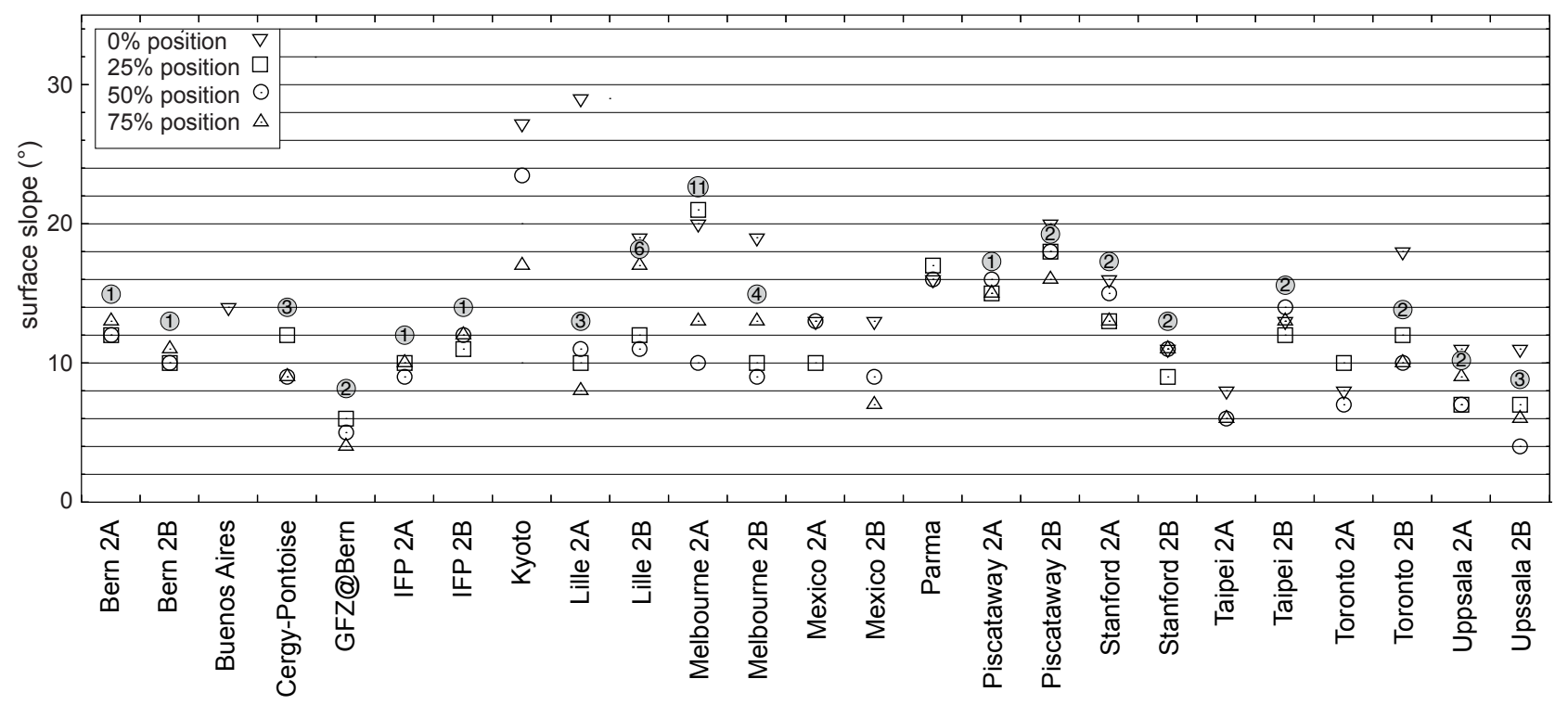



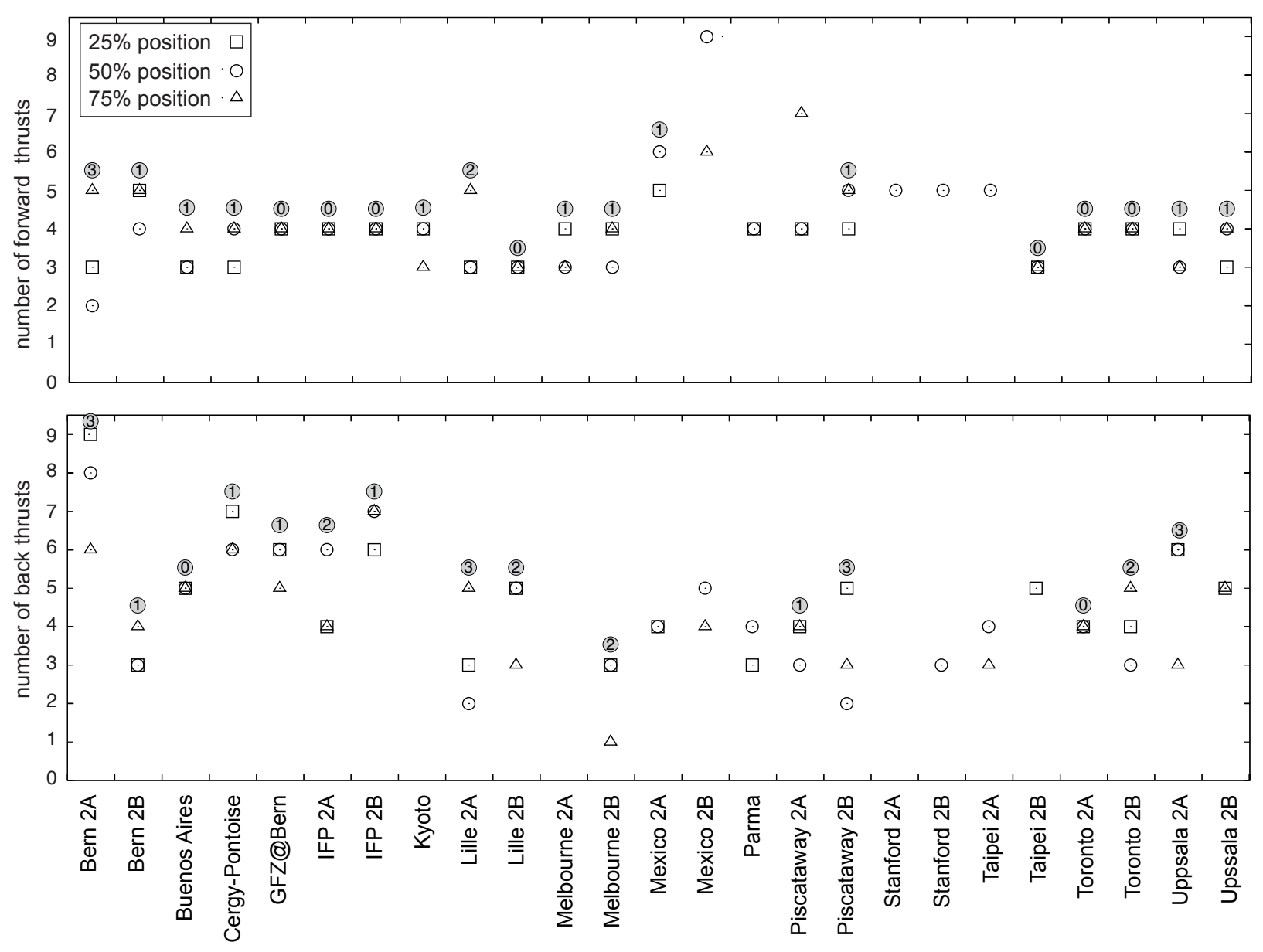


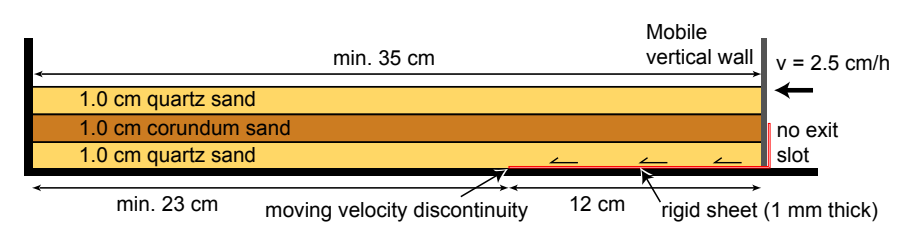



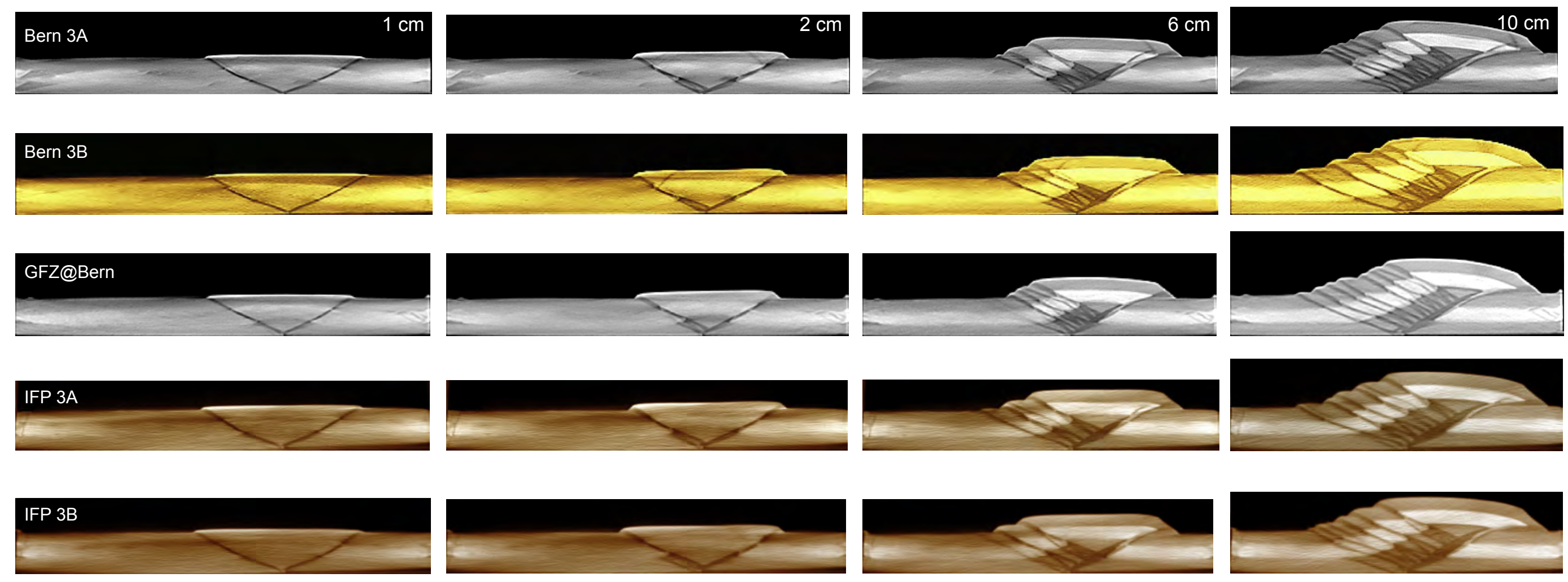

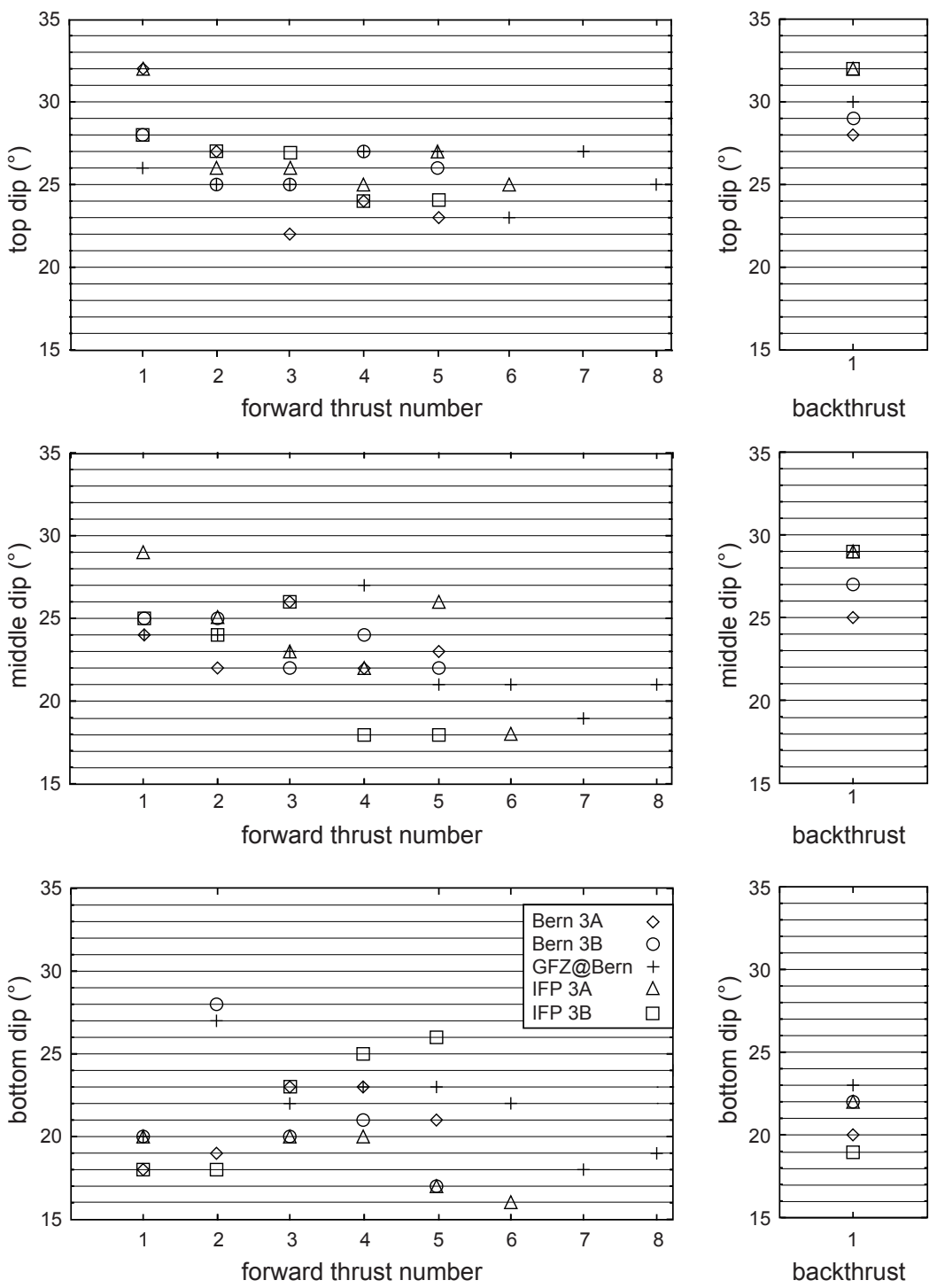


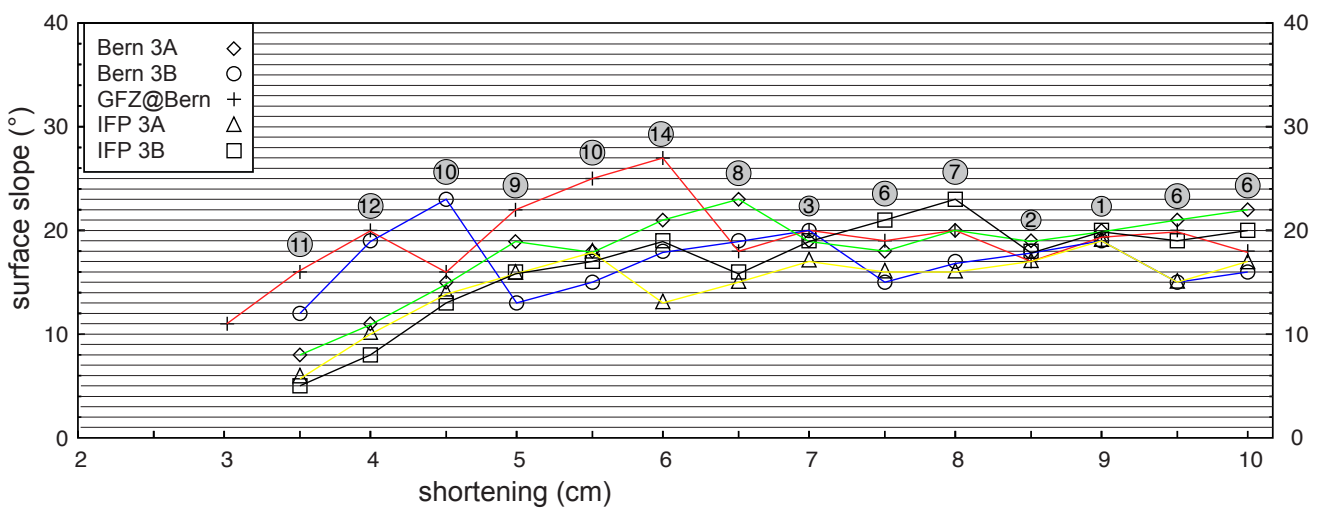



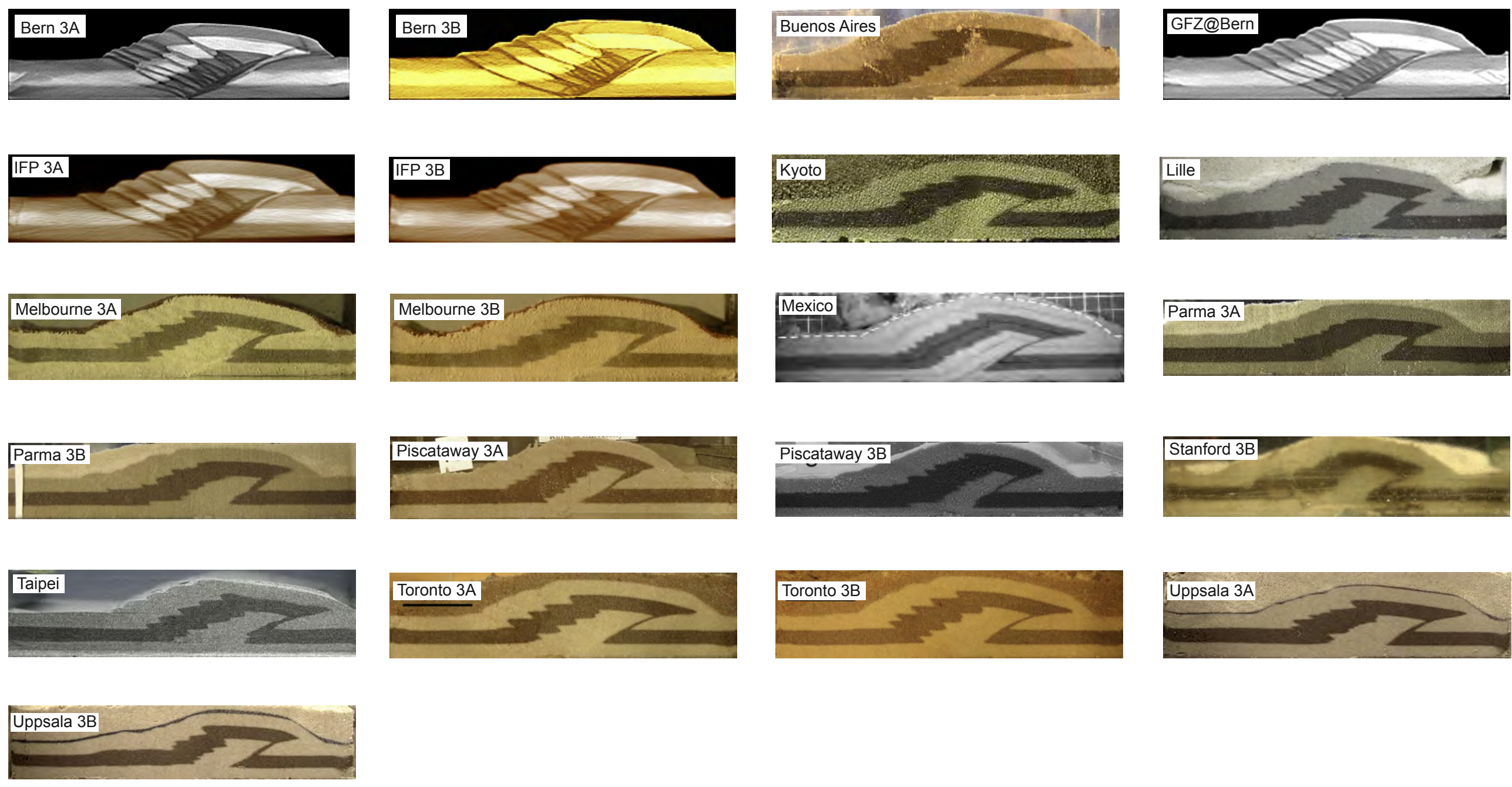

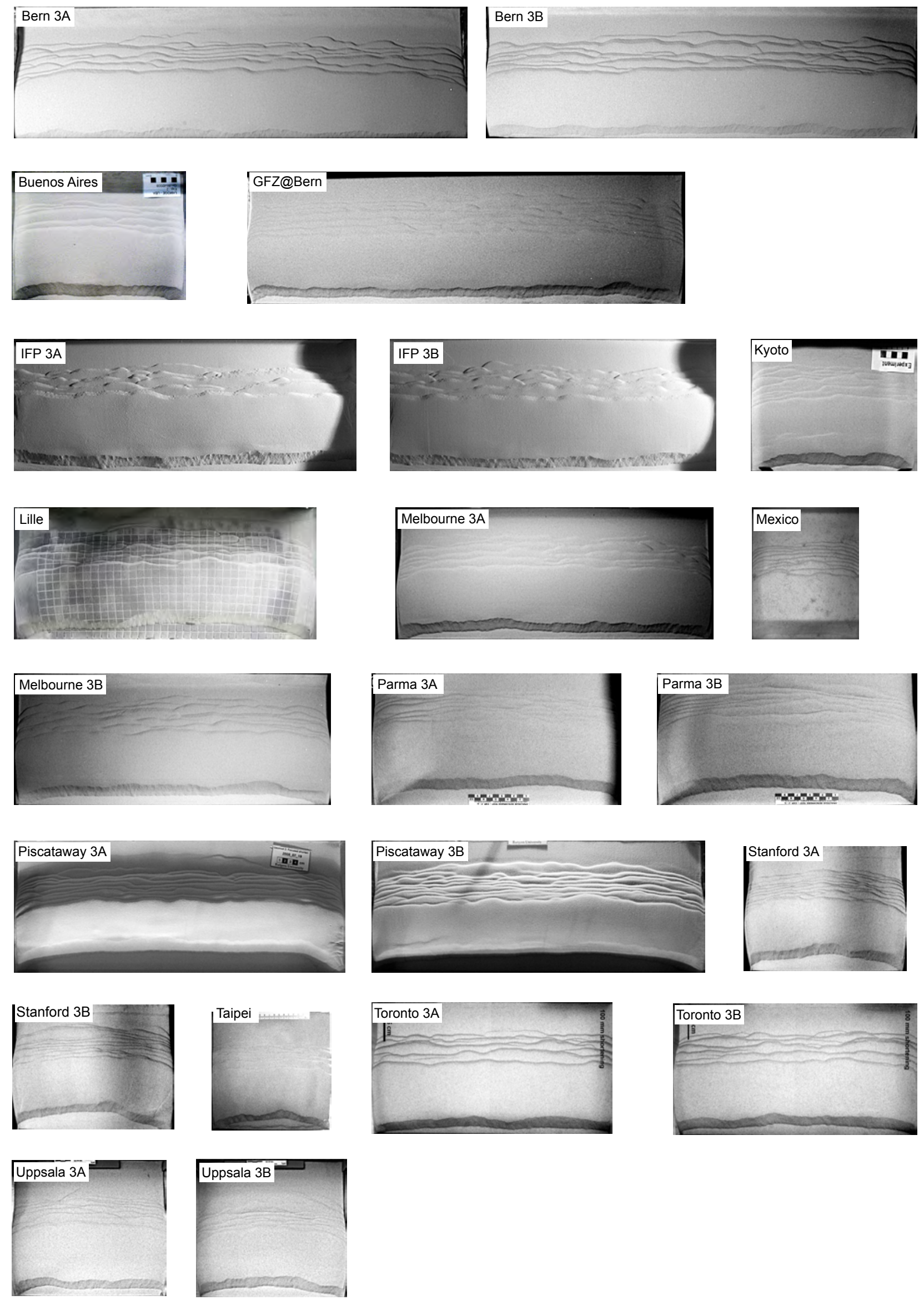


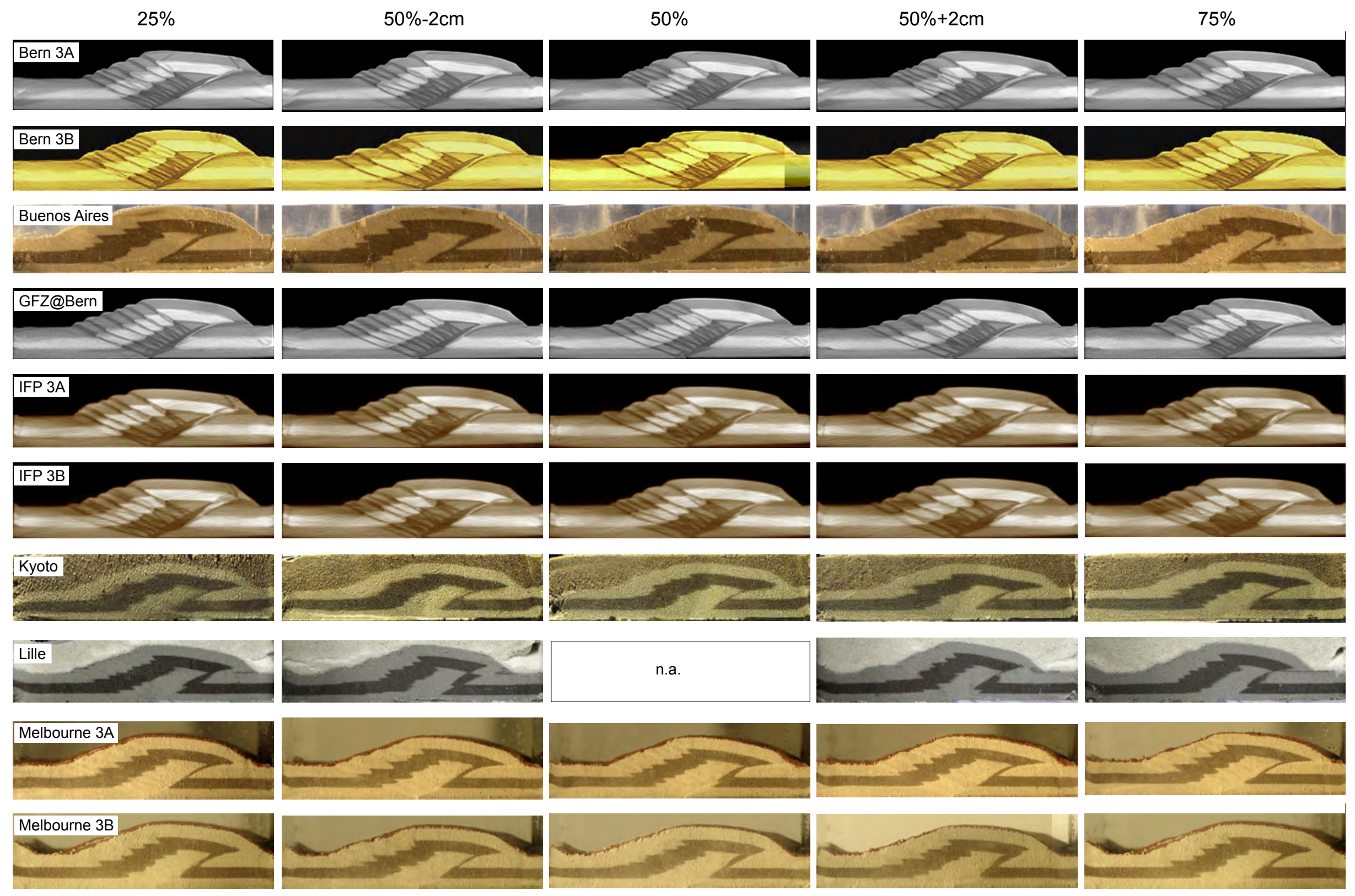




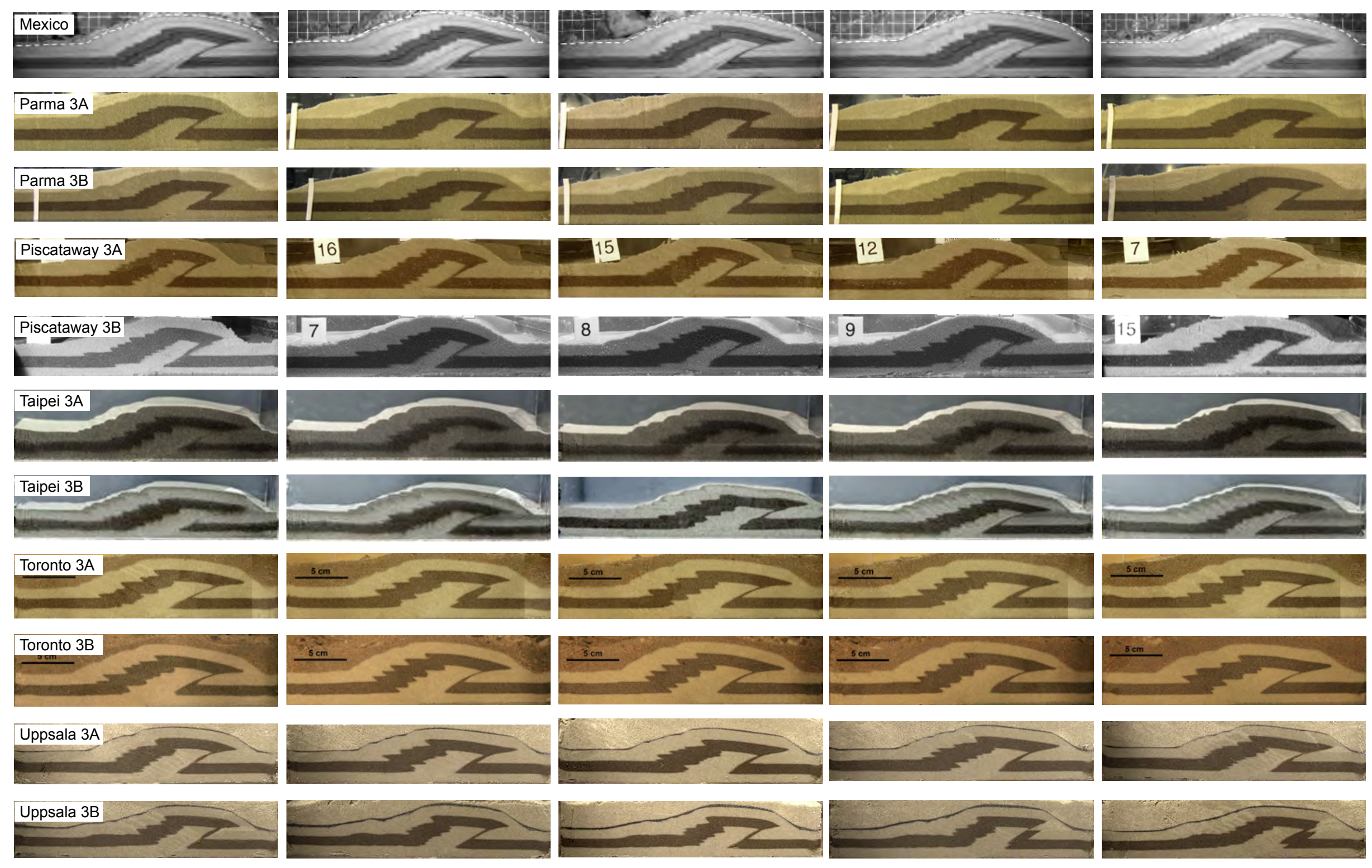




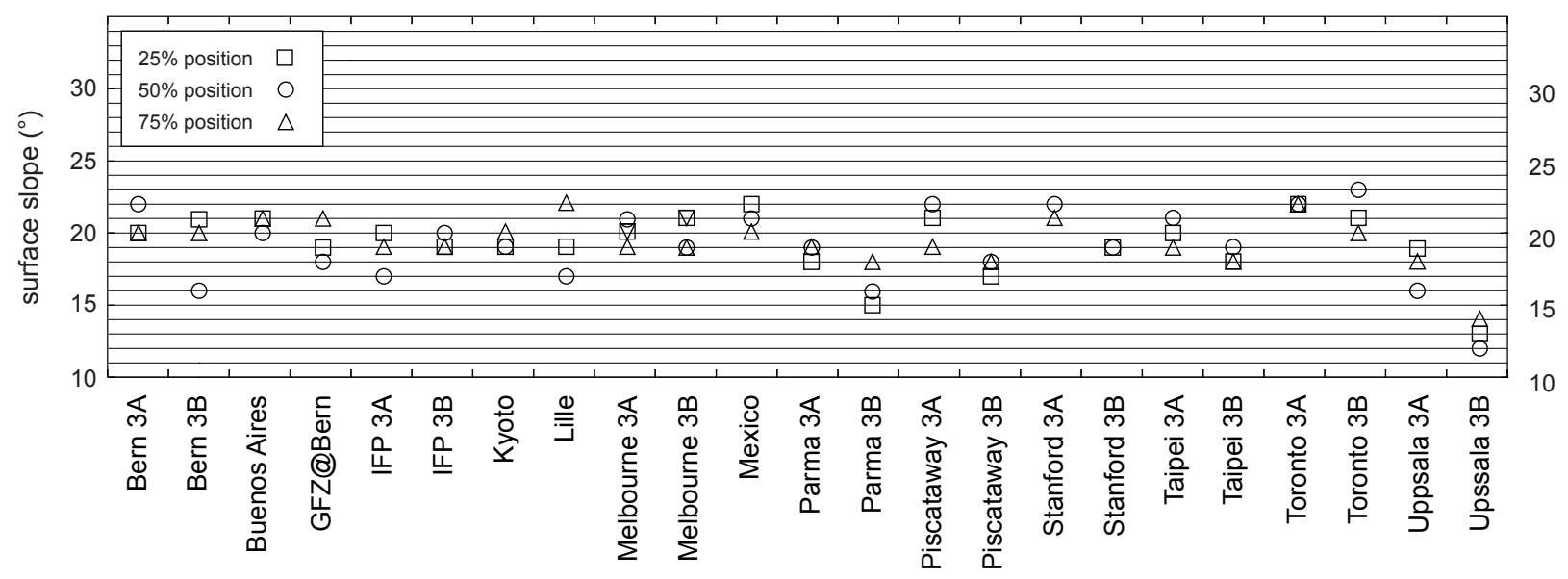




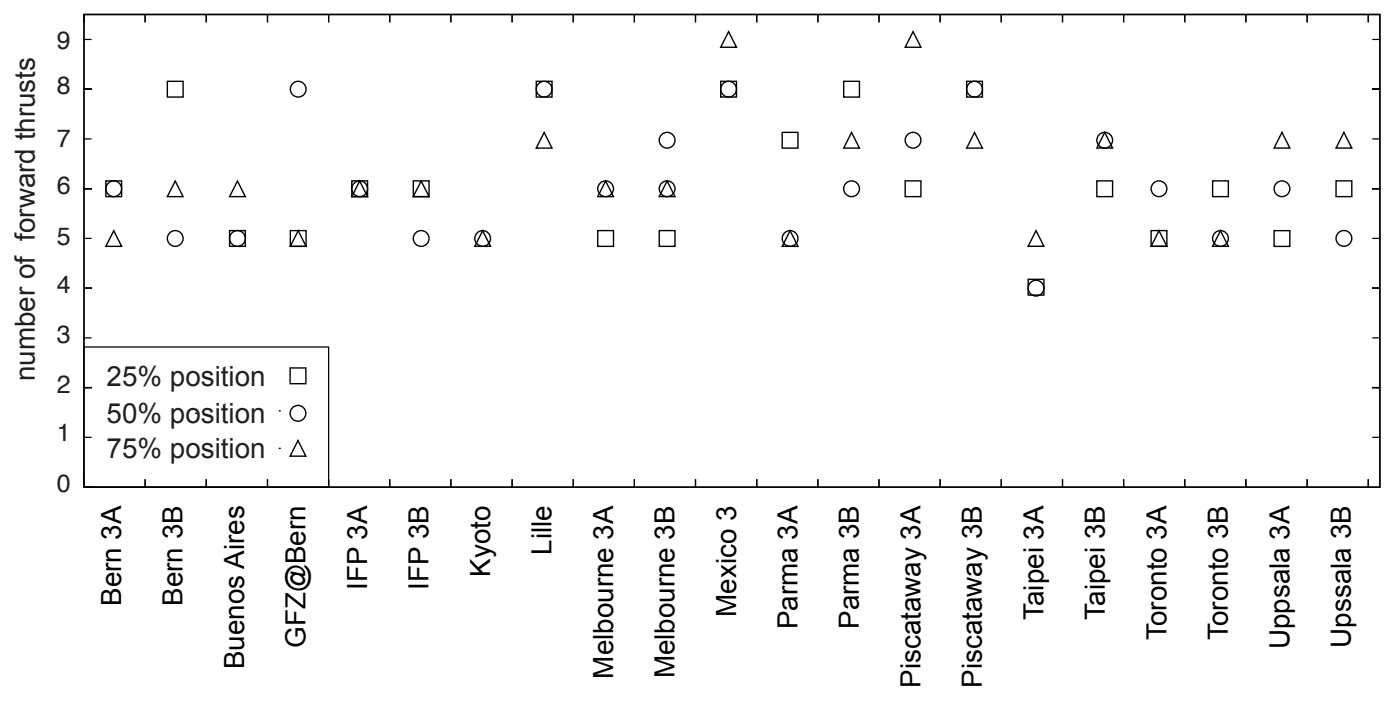


Appendix A-1: Mesh sieve

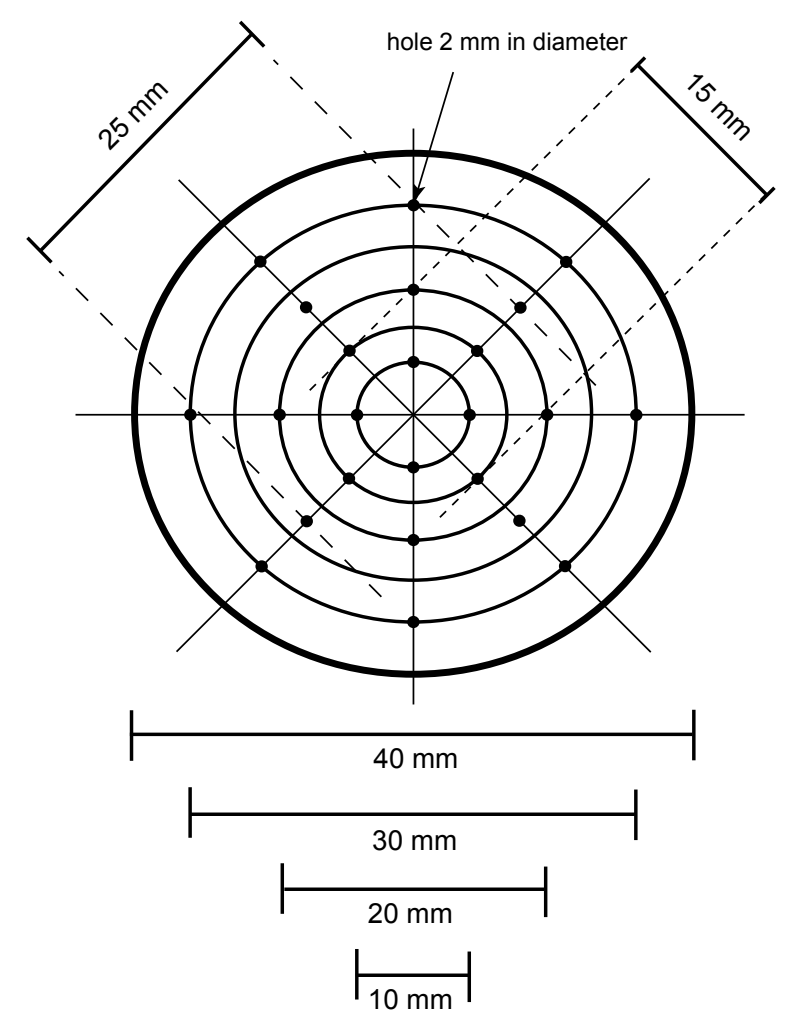




\section{Appendix A-2: Scraper to remove excess sand}

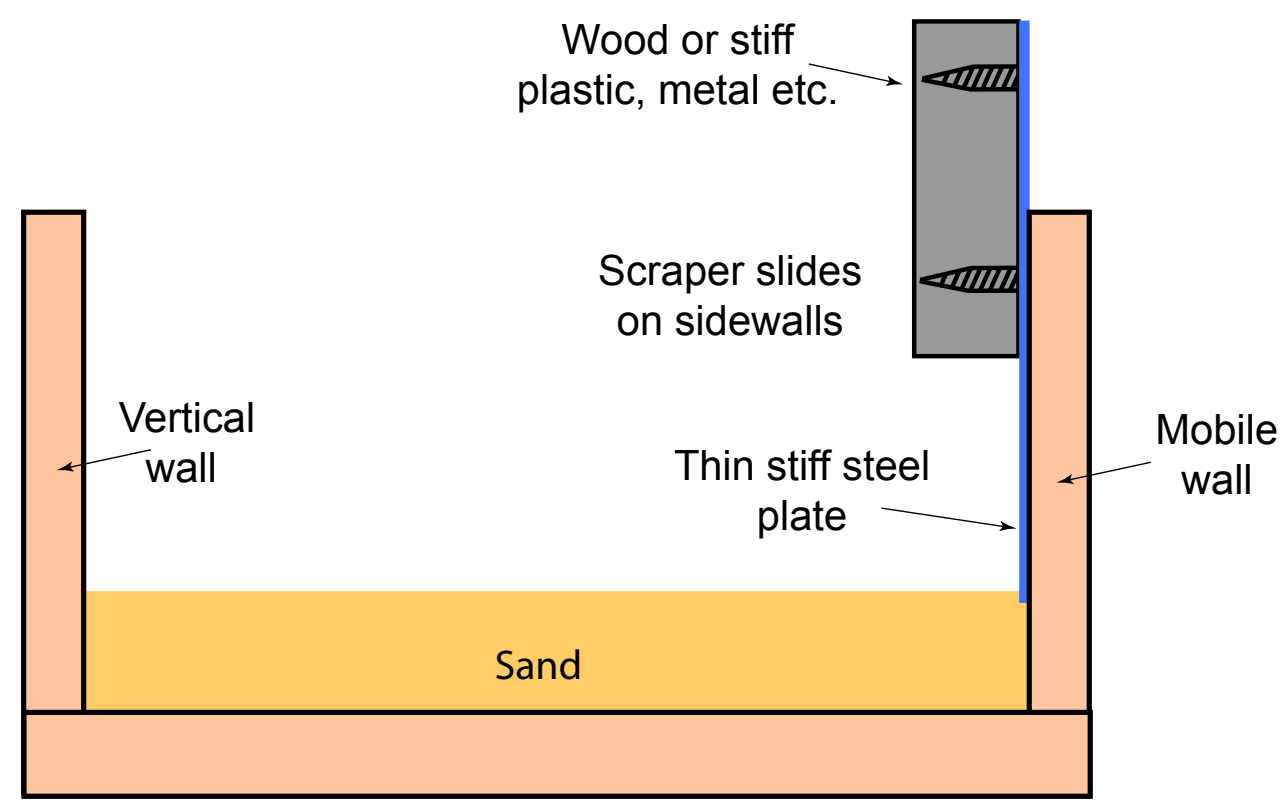

Side view (lateral sidewall omitted for clarity)

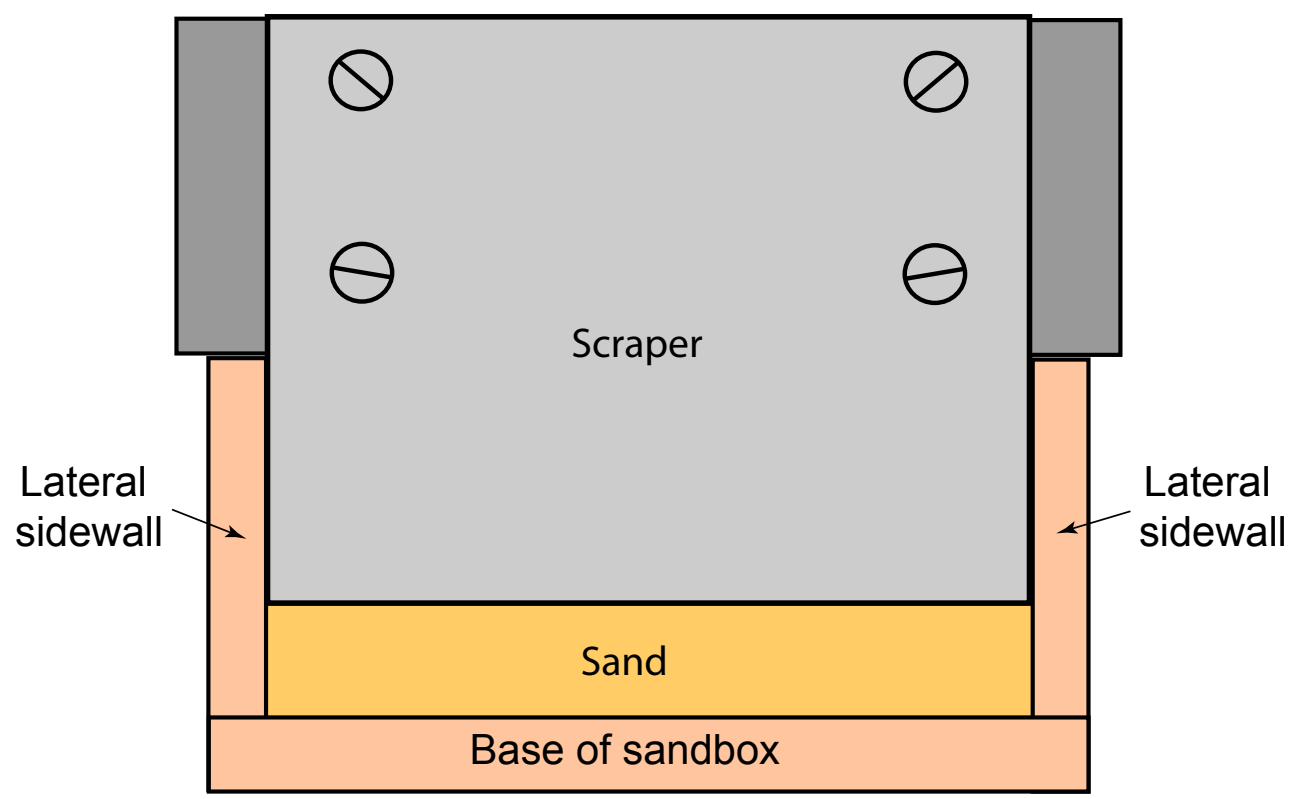

Frontal view (vertical mobile wall omitted for clarity) 
Mechanical parameter

Quartz sand

$\mathrm{n}=3$

$34^{\circ}-37^{\circ}$

$35^{\circ}-36^{\circ}$

Cohesion at peak strength $\left(\mathrm{C}_{\mathrm{p}}\right)$ in $\mathrm{Pa}$

Angle of internal friction at stable strength $\left(\phi_{\mathrm{s}}\right)$

Angle of boundary friction $\left(\phi_{b}\right)$

Boundary cohesion $\left(\mathrm{C}_{\mathrm{b}}\right)$ in $\mathrm{Pa}$

Angle of boundary friction at stable strength $\left(\phi_{\mathrm{bs}}\right)$
$19-69$

$15-28$

$30^{\circ}-31^{\circ}$

$31^{\circ}$

$15^{\circ}-21^{\circ}$

$23^{\circ}-25^{\circ}$

$14-141$

$23-44$

$9^{\circ}-14^{\circ}$

$22^{\circ}-24^{\circ}$

Table 1. Range of mechanical properties of quartz and corundum sand obtained with a ring-shear tester. Values are rounded to nearest degree for friction angles and to nearest whole number for cohesion. $n$ is number of ring-shear tests at normal stresses ranging from c. 500 to $2240 \mathrm{~Pa}$. 


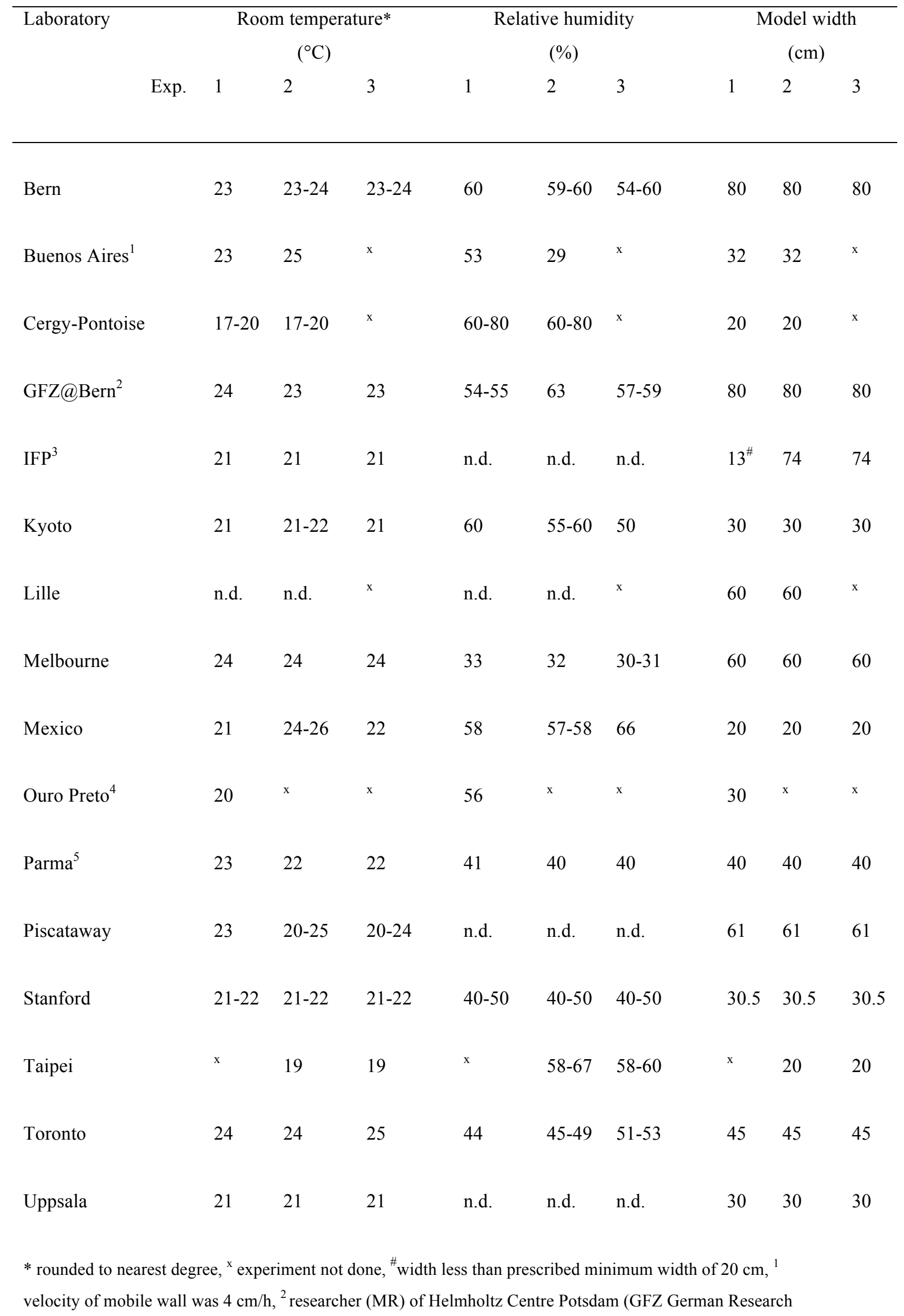


Centre for Geosciences) performed experiments 1, 2 and 3 using experimental apparatus from Bern, ${ }^{3}$ transverse walls in experiment 3 consisted of rubber sheets, ${ }^{4}$ velocity of mobile wall $2.3 \mathrm{~cm} / \mathrm{h},{ }^{5}$ velocity of mobile wall 5 $\mathrm{cm} / \mathrm{h}$, n.d. $=$ not determined

Table 2. Overview of laboratory climatic conditions and model widths. Most laboratories performed experiments 2 and 3 twice, and range of values for room temperature and relative humidity are indicated. Exceptions to the prescribed modeling procedure are also given. 